\title{
Targeting redox homeostasis in rhabdomyosarcoma cells: GSH-depleting agents enhance auranofin-induced cell death
}

\author{
Karoline Johanna Habermann ${ }^{1}$, Leon Grünewald ${ }^{1}$, Sjoerd van Wijk ${ }^{1}$ and Simone Fulda ${ }^{\star, 1,2,3}$
}

Rhabdomyosarcoma (RMS) cells have recently been reported to be sensitive to oxidative stress. Therefore, we investigated whether concomitant inhibition of the two main antioxidant defense pathways, that is, the thioredoxin (TRX) and the glutathione (GSH) systems, presents a new strategy to trigger cell death in RMS. In this study, we discover that GSH-depleting agents, i.e. $\gamma$-glutamylcysteine synthetase inhibitor, buthionine sulfoximine (BSO) or the cystine/glutamate antiporter inhibitor erastin (ERA), synergize with thioredoxin reductase (TrxR) inhibitor auranofin (AUR) to induce cell death in RMS cells. Interestingly, AUR causes accumulation of ubiquitinated proteins when combined with BSO or ERA, in line with recent reports showing that AUR inhibits the proteasome besides TrxR. Consistently, AUR/BSO or AUR/ERA cotreatment increases ubiquitination and expression of the short-lived proteins NOXA and MCL-1, accompanied by increased binding of NOXA to MCL-1. Notably, NOXA knockdown significantly rescues RMS cells from AUR/ BSO- or AUR/ERA-induced cell death. In addition, AUR acts together with BSO or ERA to stimulate BAX/BAK and caspase activation. Of note, BSO or ERA abolish the AUR-stimulated increase in GSH levels, leading to reduced GSH levels upon cotreatment. Although AUR/ BSO or AUR/ERA cotreatment enhances reactive oxygen species (ROS) production, only thiol-containing antioxidants (i.e., $N$ acetylcysteine (NAC), GSH), but not the non-thiol-containing ROS scavenger $\alpha$-Tocopherol consistently suppress AUR/BSO-and AUR/ ERA-stimulated cell death in both cell lines. Importantly, re-supply of GSH or its precursor NAC completely prevents AUR/ERA- and AUR/BSO-induced accumulation of ubiquitinated proteins, NOXA upregulation and cell death, indicating that GSH depletion rather than ROS production is critical for AUR/BSO- or AUR/ERA-mediated cell death. Thus, by demonstrating that GSH-depleting agents enhance the antitumor activity of AUR, we highlight new treatment options for RMS by targeting the redox homeostasis.

Cell Death and Disease (2017) 8, e3067; doi:10.1038/cddis.2017.412; published online 5 October 2017

RMS is the most common soft-tissue sarcoma found in children $^{1}$ and comprises two major histological subtypes, that is, alveolar RMS (ARMS) and embryonal RMS (ERMS). ${ }^{2-4}$ As the prognosis especially after metastasis or relapse still remains poor, ${ }^{5}$ there is a high medical need for new therapies.

Evasion of programmed cell death belongs to the typical hallmarks of cancer ${ }^{6}$ and can contribute to tumor progression as well as to treatment resistance. ${ }^{7}$ Apoptosis is one of the most extensively studied forms of programmed cell death, consisting of the extrinsic (death receptor) and the intrinsic (mitochondrial) pathway. ${ }^{8}$ Within the latter, pro- and antiapoptotic proteins of the B-cell lymphoma (BCL-2) family are involved in regulating mitochondrial outer membrane permeabilization, resulting in caspase-dependent or -independent cell death. ${ }^{9-11}$ The relative dominance of proapoptotic compared with antiapoptotic BCL-2 family proteins determines apoptosis sensitivity via homo- or heterodimeric binding. For example, the proapoptotic BCL-2-homology 3 (BH3)-only protein NOXA promotes apoptosis by binding to the antiapoptotic protein MCL-1, thereby antagonizing its antiapoptotic function. ${ }^{12}$ Besides apoptosis, ferroptosis is another form of programmed cell death that has recently been defined. ${ }^{13}$ Ferroptosis depends on iron, as well as on lipid-based reactive oxygen species (ROS) production and lipid peroxidation. ${ }^{13,14}$
Tight regulation of the redox homeostasis is of vital importance for cells. At low concentrations, ROS exert important functions in many biological and biochemical processes, whereas at high levels ROS can lead to cell death. ${ }^{15}$ Cancer cells often exhibit increased basal ROS levels, for example, because of their elevated metabolic activity, oncogene activation or mitochondrial dysfunction that are compensated by concomitant upregulation of antioxidant pathways to cope with higher levels of oxidative stress. ${ }^{16}$ These changes render cancer cells particularly susceptible to treatment regimens targeting their redox homeostasis. ${ }^{17}$

The glutathione (GSH) and the thioredoxin (TRX) system are two important ROS scavenging pathways that are often upregulated in cancer cells. ${ }^{18,19}$ As the reduced form of GSH is the most abundant non-protein thiol in the cell, ${ }^{20}$ changes in intracellular GSH levels have an important role in regulating redox homeostasis. As key antioxidant systems can display widespread redundant functions, ${ }^{21-25}$ simultaneous inhibition of more than one pathway may be required to cause oxidative stress in cancer cells.

Several pharmacological agents can inhibit antioxidant pathways. For example, BSO inhibits $\mathrm{Y}$-glutamylcysteine synthetase, $^{26}$ the rate-limiting enzyme of the GSH synthesis, ${ }^{27}$ leading to GSH depletion. ${ }^{26,27}$ ERA blocks the

\footnotetext{
${ }^{1}$ Institute for Experimental Cancer Research in Pediatrics, Goethe-University, Komturstrasse 3a, Frankfurt, Germany; ${ }^{2}$ German Cancer Consortium (DKTK), Partner Site Frankfurt, Germany and ${ }^{3}$ German Cancer Research Center (DKFZ), Heidelberg, Germany

${ }^{*}$ Corresponding author: S Fulda, Institute for Experimental Cancer Research in Pediatrics, Goethe-University, Komturstrasse 3a, Frankfurt 60528, Germany. Tel: +49 69 67866557; Fax: +49 69 6786659157; E-mail: simone.fulda@kgu.de

Received 20.5.17; revised 14.7.17; accepted 18.7.17; Edited by G Raschellà
} 
a

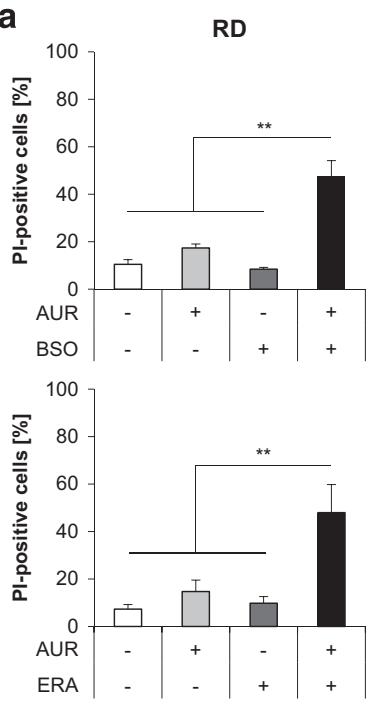

C

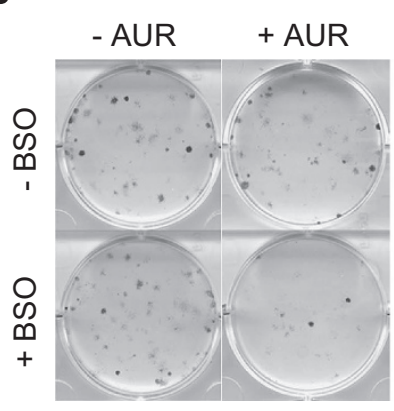

d

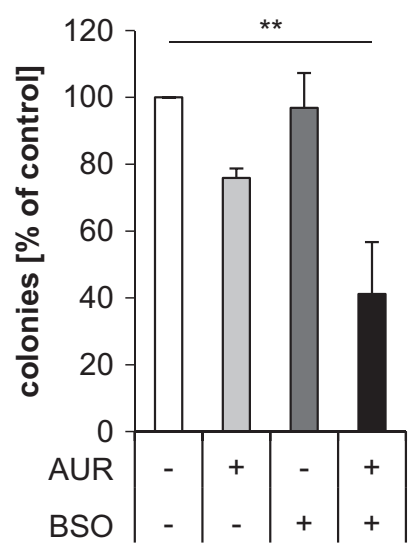

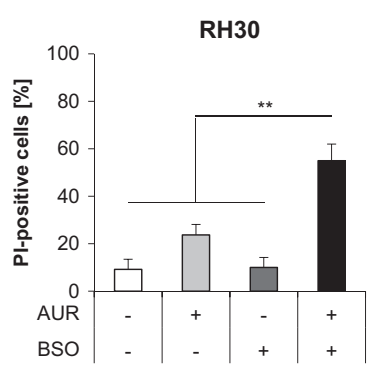

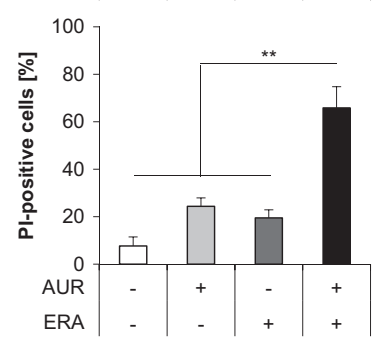

RD

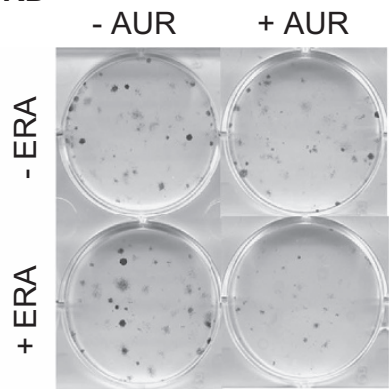

RD

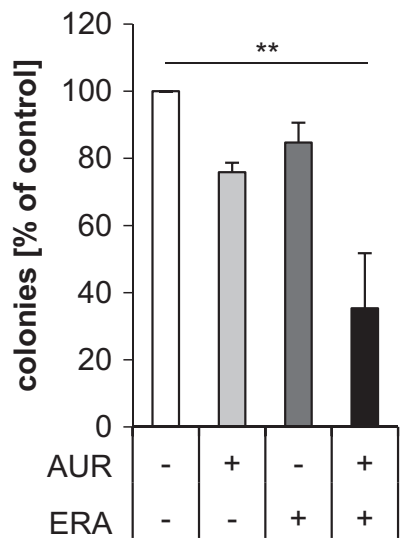

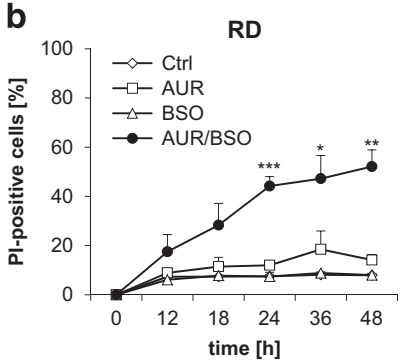
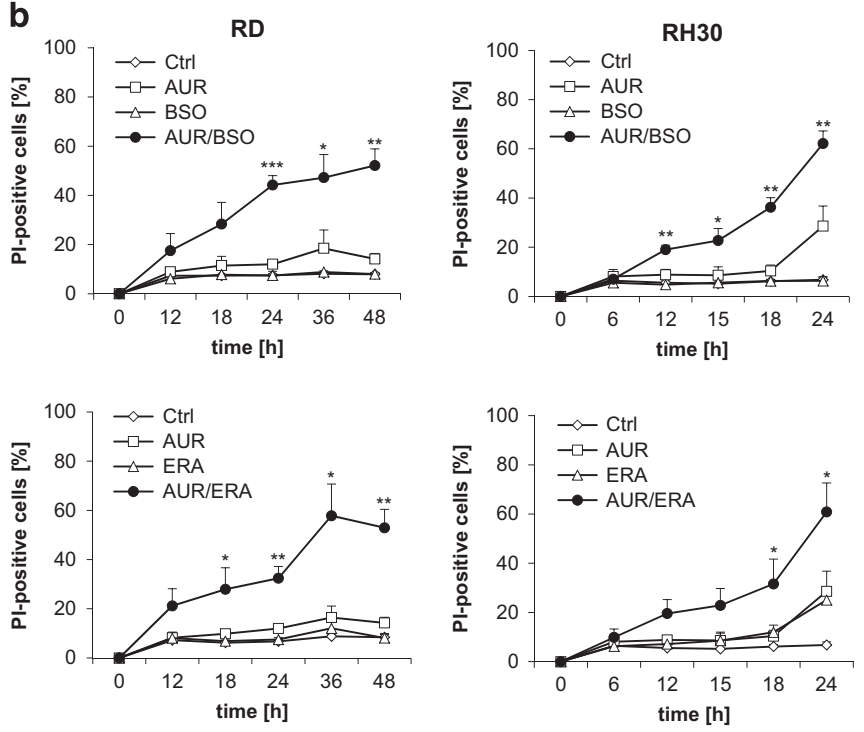

RH30
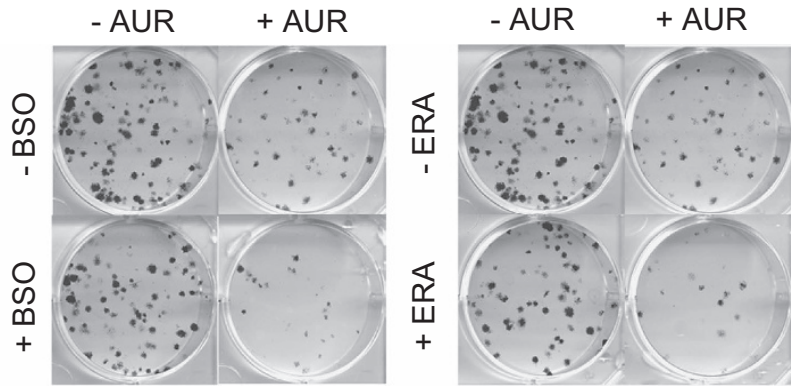

RH30
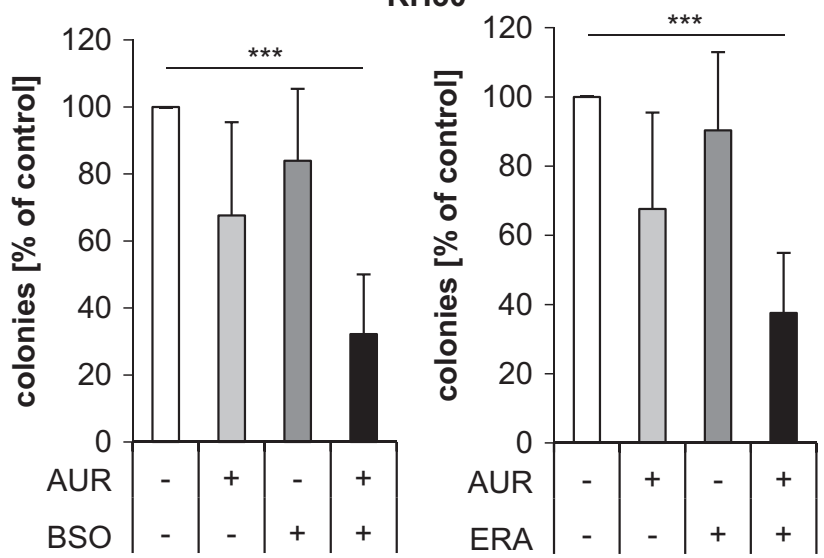

Figure 1 GSH-depleting drugs enhance AUR-induced cell death and suppression of colony formation. (a) RMS cells were treated for $24 \mathrm{~h}$ (RH30) or $48 \mathrm{~h}$ (RD) with $1 \mu \mathrm{M}$ AUR and/or $1 \mu \mathrm{M} \mathrm{BSO}$ and/or ERA (RH30: $1 \mu \mathrm{M}, \mathrm{RD}: 2 \mu \mathrm{M}$ ). Cell death was determined by PI staining using flow cytometry. Mean and S.D. of at least three independent experiments carried out in triplicate are shown; ${ }^{* *} P \leq 0.01$. (b) RMS cells were treated with $1 \mu \mathrm{M}$ AUR and/or $1 \mu \mathrm{M}$ BSO and/or ERA (RH30: $1 \mu \mathrm{M}, \mathrm{RD}: 2 \mu \mathrm{M}$ ) for indicated times. Cell death was determined by PI staining using flow cytometry. Mean and S.D. of at least three independent experiments carried out in triplicate are shown; ${ }^{*} P \leq 0.05,{ }^{* *} P \leq 0.01$, ${ }^{* \star *} P \leq 0.001$ (c and d) Cells were treated with $1 \mu \mathrm{M}$ AUR and/or $1 \mu \mathrm{M} \mathrm{BSO}$ and/or ERA (RH30: $1 \mu \mathrm{M}, \mathrm{RD}: 2 \mu \mathrm{M}$ ) and colony formation was assessed after 10-12 days as described in the Materials and methods section. The number of colonies is expressed as percentage of untreated controls (d) and representative images are shown (c). Mean and S.D. of at least three independent experiments carried out in triplicate are shown; ${ }^{* *} P \leq 0.01,{ }^{* \star} P \leq 0.001$

cystine/glutamate antiporter at the plasma membrane ${ }^{13}$ that is responsible for the intracellular uptake of cystine, an essential precursor for GSH synthesis. ${ }^{27}$ AUR is a well-known inhibitor of thioredoxin reductase (TrXR), ${ }^{28}$ causing a deficiency of the reduced form of TRX, an important ROS scavenging enzyme. ${ }^{29}$ In addition, AUR has recently been described to block proteasome-associated deubiquitinases (DUBs), thereby inhibiting degradation of ubiquitinated proteins. ${ }^{30}$ 
Recent genomic analysis of primary RMS samples revealed features of oxidative damage-induced mutations, pointing to increased oxidative stress in RMS. ${ }^{31}$ In addition, RMS have been shown to upregulate de novo synthesis of $\mathrm{GSH}^{32}$ indicating that RMS cells increase ROS scavenging systems to cope with elevated ROS levels. Furthermore, there is recent evidence showing that RMS cells may be sensitive to ROS-inducing agents. ${ }^{31}$ Against this background, we investigated in this study whether targeting the cellular redox homeostasis represents a suitable approach to induce cell death in RMS.

\section{Results}

GSH-depleting drugs enhance AUR-induced cell death and suppression of colony formation. To test the hypothesis that concomitant inhibition of the two major antioxidant defense pathways provides a novel strategy to trigger programmed cell death in RMS cells, we blocked in parallel the GSH system by using BSO or ERA and the TRX system by using AUR. The ERMS cell line RD and the ARMS cell line $\mathrm{RH} 30$ were used as cellular models to represent the two major histopathological subtypes of RMS.

Of note, AUR cooperated with BSO or ERA to significantly increase cell death compared with treatment with either agent alone in both RMS cell lines (Figure 1a). Calculation of combination indices (Cls) showed that the interaction of AUR with BSO or ERA was synergistic (Supplementary Figure 1, Supplementary Tab. 1). Kinetic analysis demonstrated a timedependent induction of cell death by AUR together with BSO or ERA (Figure 1b).

To explore whether the combination treatments also have an impact on long-term clonogenic survival, we performed colony assays. AUR/BSO cotreatment, as well as AUR/ERA cotreatment significantly diminished the number of colonies compared with untreated controls (Figures $1 \mathrm{c}$ and $\mathrm{d}$ ). These findings demonstrate that GSH-depleting drugs enhance AUR-induced cell death and suppression of colony formation in RMS cells.

AUR/BSO or AUR/ERA cotreatment triggers ROS production. To unravel the underlying mechanisms of synergistic cell death, we determined ROS production. AUR/BSO or AUR/ERA cotreatment significantly increased ROS production in comparison with untreated controls (Figure 2a). To investigate the requirement of ROS for cell death, we used ROS scavengers. Interestingly, the thiol-containing antioxidant and GSH precursor $N$-acetylcysteine (NAC) profoundly suppressed AUR/BSO- and AUR/ERA-stimulated ROS production, as well as cell death (Figures $2 a$ and b). In contrast, the non-thiol-containing ROS scavenger $a$-Tocopherol ( $a$-Toc) only partially rescued $\mathrm{RH} 30$, but not RD cells from AUR/BSOinduced ROS production and cell death, whereas it protected both RMS cell lines from AUR/ERA-induced ROS production and cell death (Figures $2 a$ and $b$ ). These findings suggest that ROS do contribute but do not solely account for the combination treatment-induced cell death.

AUR/BSO or AUR/ERA cotreatment causes proteasome inhibition and increases ubiquitination and expression of NOXA and MCL-1. As AUR has recently been reported to
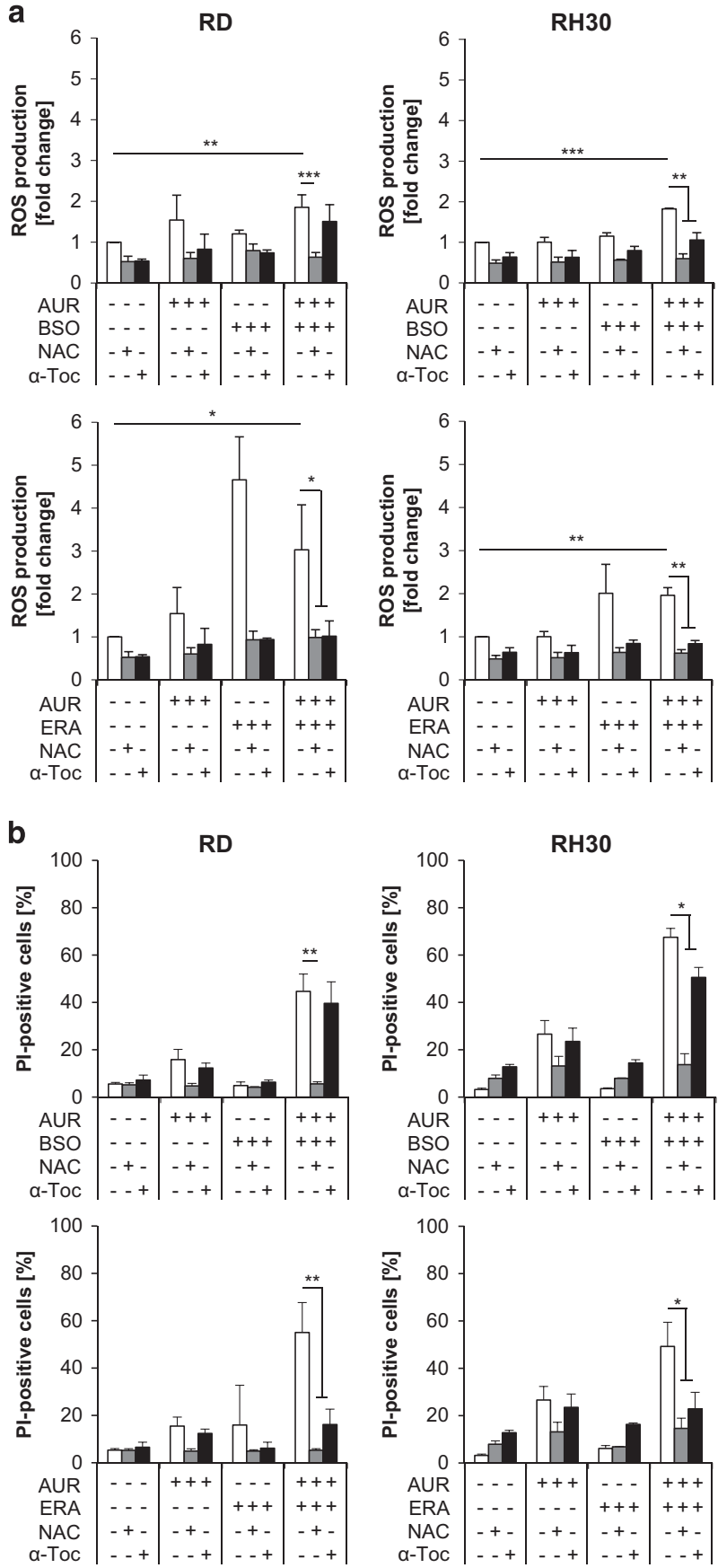

Figure $2 A U R / B S O$ or AUR/ERA cotreatment triggers ROS production. (a) RMS cells were treated for $15 \mathrm{~h}(\mathrm{RH} 30)$ and $18 \mathrm{~h}(\mathrm{RD})$ with $1 \mu \mathrm{M}$ AUR and/or $1 \mu \mathrm{M}$ BSO and/or ERA (RH30: $1 \mu \mathrm{M}, \mathrm{RD}: 2 \mu \mathrm{M}$ ) in the presence and absence of $10 \mathrm{mM} \mathrm{NAC}$ or $100 \mu \mathrm{M} \alpha$-Toc, which were added $1 \mathrm{~h}$ before treatment. ROS production was determined by FACS analysis of the viable cell population using the fluorescent dye CM-H2DCFDA and is shown as $x$-fold ROS production compared with control. Mean and S.D. of at least three independent experiments carried out in triplicate are shown; ${ }^{*} P \leq 0.05,{ }^{* *} P \leq 0.01,{ }^{* *} P \leq 0.001$. (b) RMS cells were treated for $24 \mathrm{~h}(\mathrm{RH} 30)$ or $48 \mathrm{~h}$ (RD) with $1 \mu \mathrm{M}$ AUR and/or $1 \mu \mathrm{M} \mathrm{BSO}$ and/or ERA (RH30: $1 \mu \mathrm{M}, \mathrm{RD}: 2 \mu \mathrm{M}$ ) in the presence and absence of $10 \mathrm{mM}$ NAC or $100 \mu \mathrm{M} \alpha$-Toc, which were added $1 \mathrm{~h}$ before treatment. Cell death was determined by PI staining using flow cytometry. Mean and S.D. of at least three independent experiments carried out in triplicate are shown; ${ }^{*} P \leq 0.05,{ }^{* \star} P \leq 0.01$ 
a

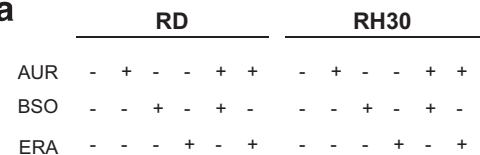

Ub-prs
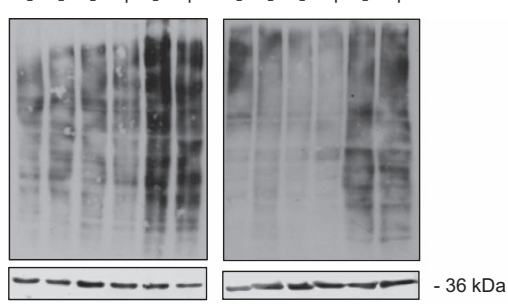

C

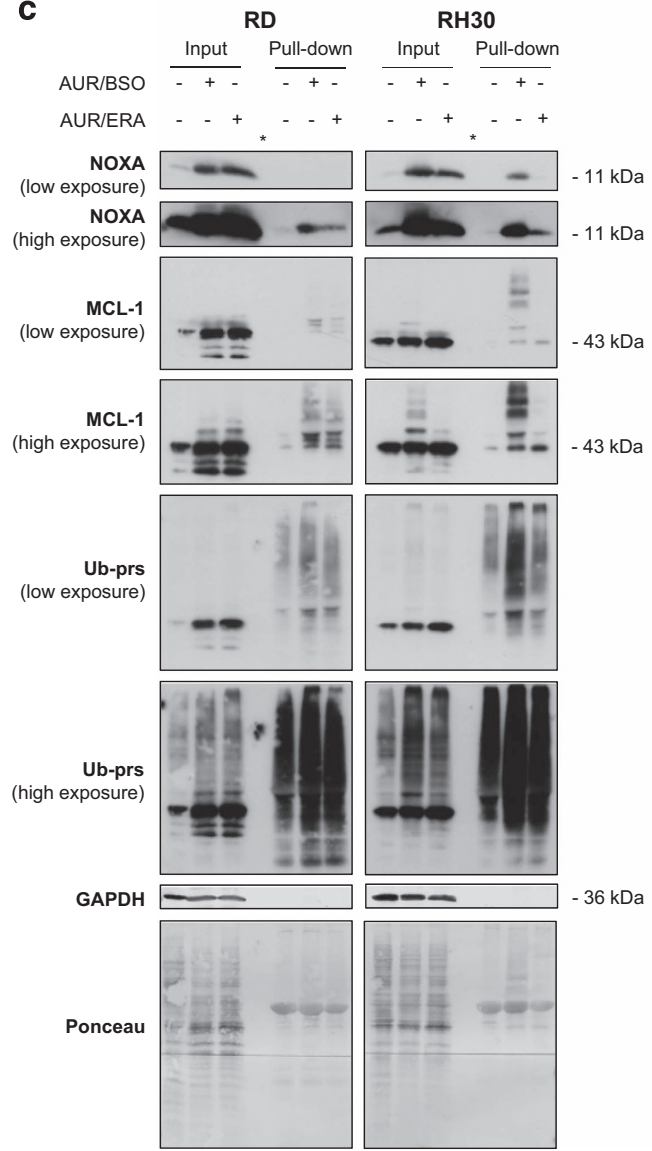

b

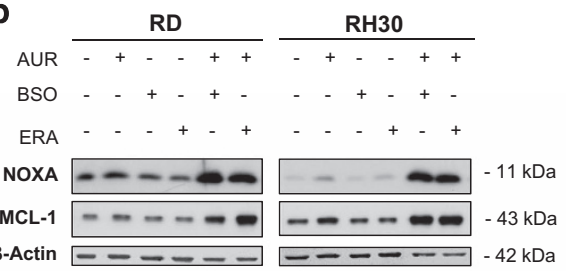

d
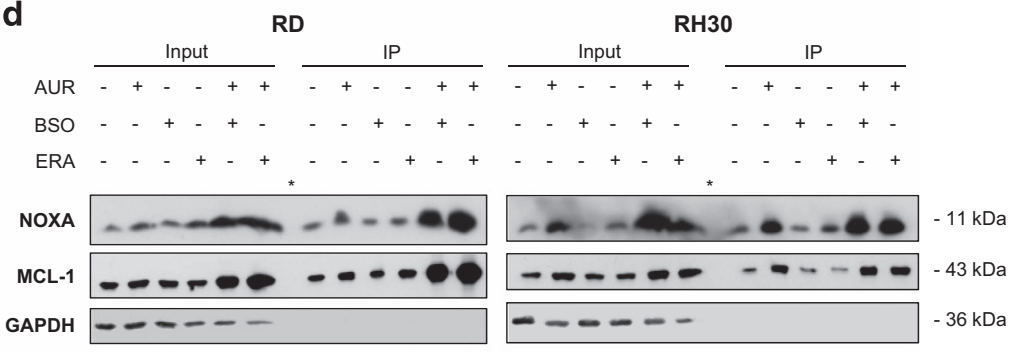

e

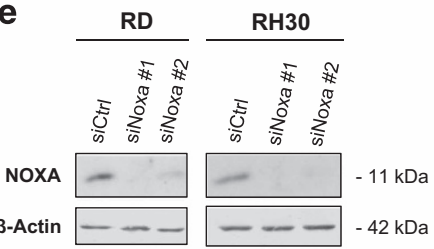

f

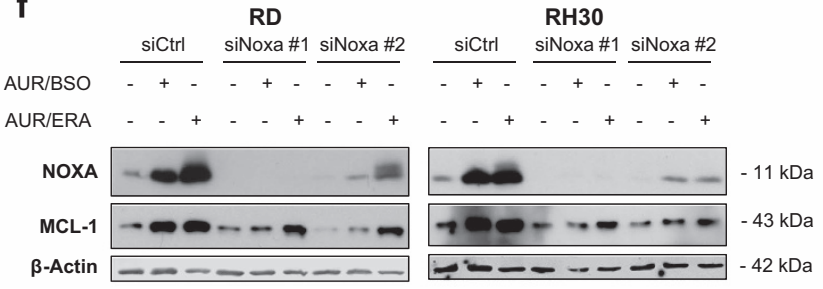

Figure 3 AUR/BSO or AUR/ERA cotreatment causes proteasome inhibition and increases ubiquitination and expression of NOXA and MCL-1. (a) RMS cells were treated for $18 \mathrm{~h}(\mathrm{RH} 30)$ and $24 \mathrm{~h}(\mathrm{RD})$ with $1 \mu \mathrm{M}$ AUR and/or $1 \mu \mathrm{M}$ BSO and/or ERA (RH30: $1 \mu \mathrm{M}, \mathrm{RD}: 2 \mu \mathrm{M})$. The amount of ubiquitinated proteins (Ub-prs) was assessed by Western blotting, GAPDH served as loading control. (b) RMS cells were treated for $18 \mathrm{~h}$ (RH30) and $24 \mathrm{~h}$ (RD) with $1 \mu \mathrm{M}$ AUR and/or $1 \mu \mathrm{M}$ BSO and/or ERA (RH30: $1 \mu \mathrm{M}, \mathrm{RD}: 2 \mu \mathrm{M}$ ). Protein expression of NOXA and MCL-1 was assessed by Western blotting, $\beta$-actin served as loading control. (c) Cells were treated for $18 \mathrm{~h}$ (RH30) and $24 \mathrm{~h}$ (RD) with $1 \mu \mathrm{M}$ AUR and $1 \mu \mathrm{M}$ BSO or ERA (RH30: $1 \mu \mathrm{M}, \mathrm{RD}: 2 \mu \mathrm{M})$. Ubiquitination of MCL-1 and NOXA was assessed by pull-down assay using TUBE-GST-linked agarose beads. The precipitate was analyzed for Ub-prs, NOXA and MCL-1 expression by Western blotting, GAPDH and Ponceau staining served as loading control; asterisks indicate empty lane. (d) Cells were treated for $18 \mathrm{~h}(\mathrm{RH} 30)$ and $24 \mathrm{~h}(\mathrm{RD})$ with $1 \mu \mathrm{M}$ AUR and/or $1 \mu \mathrm{M}$ BSO and/or ERA (RH30: $1 \mu \mathrm{M}, \mathrm{RD}: 2 \mu \mathrm{M})$. MCL-1 was immunoprecipitated (IP). The precipitate was analyzed for MCL-1 and NOXA expression by Western blotting. GAPDH served as loading control; asterisks indicate empty lane. (e and f) RMS cells were transiently transfected with siRNA against NOXA or non-targeting control siRNA. (e) Protein expression of NOXA was assessed by Western blotting $48 \mathrm{~h}$ after knockdown. $\beta$-Actin served as loading control. (f) Cells were treated for $18 \mathrm{~h}$ (RH30) and $24 \mathrm{~h}$ (RD) after knockdown for $48 \mathrm{~h}$ with $1 \mu \mathrm{M}$ AUR and $1 \mu \mathrm{M} \mathrm{BSO}$ or ERA (RH30: $1 \mu \mathrm{M}, \mathrm{RD}: 2 \mu \mathrm{M})$. Protein expression of NOXA and MCL-1 was assessed by Western blotting. $\beta$-Actin served as loading control

repress proteasome-associated DUBs apart from inhibiting $\operatorname{TrxR},{ }^{28,30}$ we next asked whether AUR affects proteasome activity at the concentrations used in our study. To address this question, we assessed accumulation of total ubiquitinated proteins as a marker of proteasome inhibition by
Western blot analysis using an antibody against ubiquitinated proteins. Interestingly, cotreatment with AUR/BSO or AUR/ERA caused accumulation of ubiquitinated proteins, whereas treatment with AUR alone had little effects (Figure 3a). As inhibition of the proteasome has been shown to result in 
upregulation of short-lived proteins, we investigated expression levels and the ubiquitination status of NOXA and MCL-1, two proteins of the BCL-2 family with a rapid turnover. ${ }^{33,34}$
Consistent with the ability of AUR/BSO or AUR/ERA to inhibit the proteasome (Figure $3 a$ ), these cotreatments resulted in upregulation of NOXA and MCL-1 protein levels, whereas a

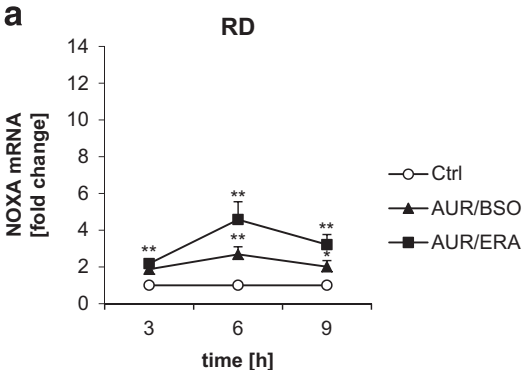

b
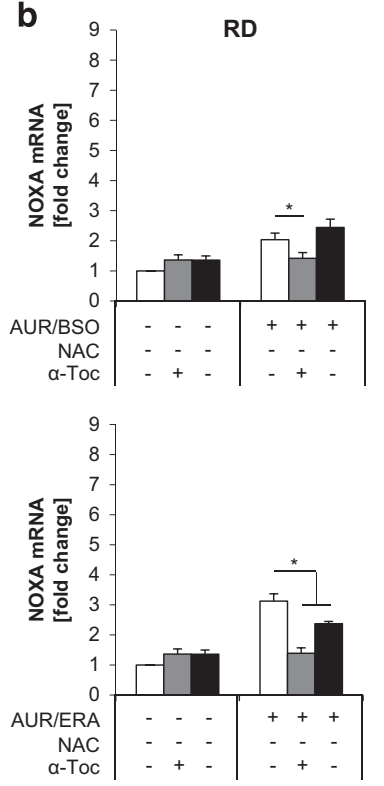

C
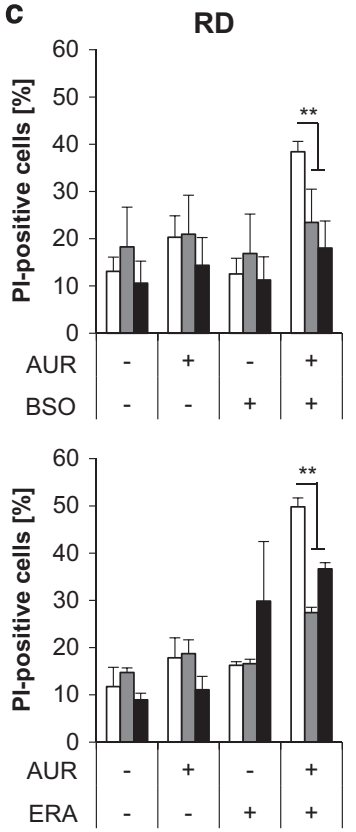

口 siCtrl

口 siNoxa \#1

- siNoxa \#2

$\square$ siCtrl

口 siNoxa \#1

- siNoxa \#2
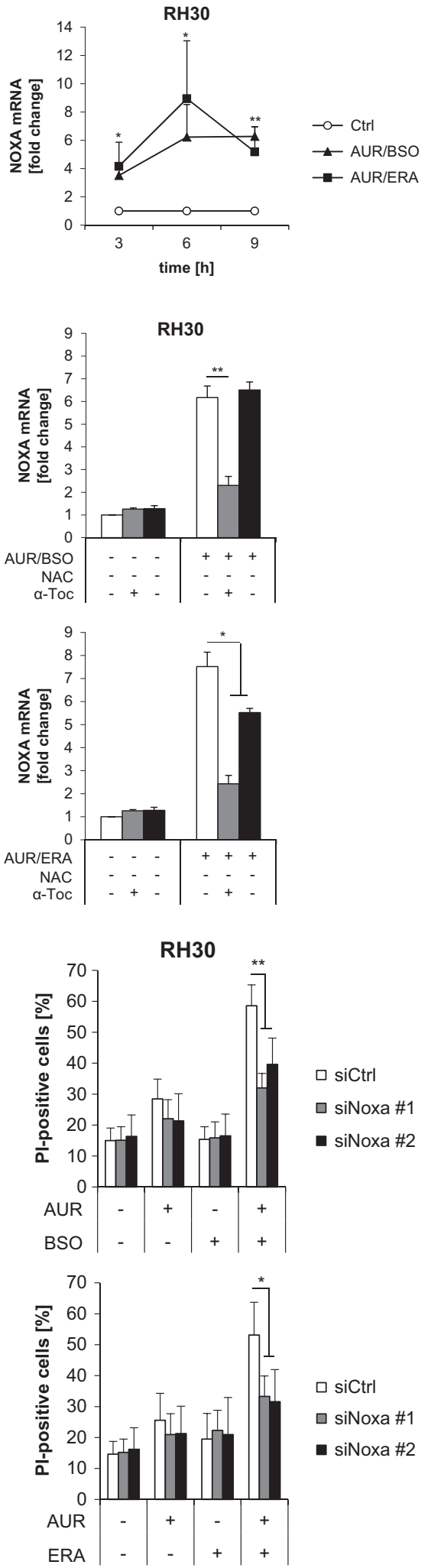

$\square$ siCtrl

口 siNoxa \#1

- siNoxa \#2 
AUR alone had little effects (Figure 3b). To specifically analyze the ubiquitination status of NOXA and MCL-1, we precipitated ubiquitinated proteins using a tandem ubiquitin-binding entity (TUBE) pull-down assay $^{35}$ and then probed for binding of NOXA and MCL-1 by Western blotting. This revealed that AUR/BSO or AUR/ERA cotreatment enhanced ubiquitination of NOXA and MCL-1 (Figure 3c). Thus, AUR/BSO or AUR/ERA cotreatment causes proteasome inhibition and increases ubiquitination and expression of NOXA and MCL-1.

As NOXA has been reported to bind to MCL-1 thereby antagonizing its antiapoptotic function, ${ }^{12}$ we next assessed the interaction of NOXA and MCL-1. Indeed, coimmunoprecipitation experiments revealed increased binding of NOXA to MCL-1 upon AUR/BSO or AUR/ERA cotreatment (Figure $3 d$ ). We then explored whether genetic silencing of NOXA has an impact on MCL-1 levels. Western blot analysis confirmed that two distinct siRNA sequences caused an efficient silencing of NOXA (Figure 3e). Of note, NOXA knockdown attenuated the AUR/BSO- or AUR/ERA-stimulated increase in $\mathrm{MCL}-1$ expression (Figure $3 \mathrm{f}$ ), indicating that NOXA contributes to MCL-1 accumulation upon these cotreatments.

NOXA contributes to AUR/BSO- and AUR/ERA-induced cell death. To determine whether AUR-based cotreatments also affect mRNA levels of NOXA, we performed quantitative real-time PCR (qRT-PCR) analysis. AUR/BSO or AUR/ERA cotreatment significantly increased NOXA mRNA levels (Figure 4a). Although addition of NAC blocked the AUR/BSO- or AUR/ERA-stimulated increase in NOXA mRNA levels, $a$-Toc partly reduced the increase in NOXA mRNA levels in AUR/ERA-treated, but not in AUR/BSO-treated cells (Figure 4b). These findings indicate that $A U R / B S O$ or AUR/ERA cotreatment leads to increased NOXA mRNA, as well as protein levels.

To explore the functional relevance of NOXA for cell death induction, we knocked down NOXA by RNA interference (RNAi). Importantly, knockdown of NOXA significantly protected RMS cells from both AUR/BSO- and AUR/ERA-induced cell death (Figure 4c). This shows that NOXA contributes to AUR/BSO- and AUR/ERA-induced cell death.

\section{AUR/BSO or AUR/ERA cotreatment triggers BAX/BAK activation and loss of mitochondrial membrane potential (MMP). As NOXA is a proapoptotic BH3-only protein known to engage the intrinsic pathway of apoptosis, ${ }^{36}$ we next analyzed activation of BAX and BAK. To this end, we used active conformation-specific antibodies and immunoprecipi- tation, as BAX/BAK activation is accompanied by}

conformational changes. ${ }^{37}$ This showed that cotreatment with AUR/BSO or AUR/ERA enhanced activation of BAX and BAK compared with control (Figure 5a). To explore whether $\mathrm{BAX} / \mathrm{BAK}$ activation is relevant for cell death, we simultaneously knocked down BAX and BAK by siRNAs (Figure $5 b$ ). BAX/BAK silencing significantly reduced AUR/BSO-induced as well as AUR/ERA-induced cell death (Figure 5c). In addition, AUR and BSO or ERA cooperated to slightly increase loss of MMP (Figure $5 \mathrm{~d}$ ).

AUR/BSO- or AUR/ERA-induced cell death is largely caspase-independent. In addition, AUR/BSO and AUR/ ERA combination treatment enhanced caspase-3/-7 activity (Figure 6a) and cleavage of poly (ADP-ribose) polymerase (PARP) (Figure 6b), a typical caspase-3 substrate. ${ }^{38}$ Although the addition of the broad-range caspase inhibitor zVAD.fmk significantly reduced AUR/BSO- or AUR/ERAstimulated caspase-3/-7 activity (Figure 6a), it did not prevent the induction of cell death (Figure $6 \mathrm{c}$ ). Tumor necrosis factor (TNF)-related apoptosis-inducing ligand (TRAIL) receptor-2 agonistic antibody ETR2 was used as positive control, as it is a prototypic stimulus of caspase-dependent cell death in RMS. ${ }^{39}$ These findings show that AUR/BSO and AUR/ERA cotreatment triggers typical parameters of intrinsic apoptosis, although cell death can proceed in a caspase-independent manner when caspases are blocked.

As ERA and BSO have been reported to induce ferroptotic cell death, ${ }^{4,13}$ we investigated whether AUR/BSO- or AUR/ ERA-induced cell death exhibits ferroptotic features like lipid peroxidation. Indeed, AUR/BSO, as well as AUR/ERA cotreatment significantly increased lipid peroxidation (Figure 6d), although this increase was rather minor compared with RSL3 as a positive control (Supplementary Figure 2). Furthermore, addition of ferroptosis inhibitors including Liproxstatin-1 (Lip-1), Ferrostatin-1 (Fer-1) or the ironchelating compound deferoxamine (DFO) partially reduced AUR/BSO- and AUR/ERA-induced cell death in RH3O cells, while they had little or no protective effects in RD cells, but completely suppressed ferroptosis induced by RSL3 as positive control (Figure 6e). Consistently, $\mathrm{RH} 30$ cells were found to harbor lower constitutive protein expression of GPX4 (Figure 6f), which reduces oxidized lipid hydroperoxides within biological membranes. ${ }^{40}$ Together, these results indicate that ferroptotic signaling pathways partially contribute to AUR/ BSO- and AUR/ERA-induced cell death in RH30 cells.

BSO or ERA counteract the AUR-stimulated increase in GSH levels. To confirm that AUR inhibits TrxR, we assessed TrxR activity. Treatment with AUR alone or in combination

Figure 4 NOXA contributes to AUR/BSO- and AUR/ERA-induced cell death. (a) RMS cells were treated for indicated times with $1 \mu \mathrm{M}$ AUR and $1 \mu \mathrm{M}$ BSO or ERA (RH30: $1 \mu \mathrm{M}, \mathrm{RD}: 2 \mu \mathrm{M})$. mRNA expression of NOXA was determined by qRT-PCR, normalized to $28 \mathrm{~S}$ expression and is shown as $x$-fold mRNA expression compared with control. Mean and S.D. of at least three independent experiments carried out in duplicate are shown; ${ }^{*} P \leq 0.05,{ }^{* \star} P \leq 0.01$. (b) Cells were treated for $6 \mathrm{~h}$ with $1 \mu \mathrm{M}$ AUR and $1 \mu \mathrm{M}$ BSO or ERA (RH30: $1 \mu \mathrm{M}, \mathrm{RD}: 2 \mu \mathrm{M}$ ) in the presence and absence of $10 \mathrm{mM} \mathrm{NAC}$ or $100 \mu \mathrm{M} \alpha$-Toc, which were added $1 \mathrm{~h}$ before treatment. mRNA expression of NOXA was determined by qRT-PCR, normalized to $28 \mathrm{~S}$ expression and is shown as $x$-fold mRNA expression compared with control. Mean and S.D. of at least three independent experiments carried out in duplicate are shown; ${ }^{*} P \leq 0.05,{ }^{* \star} P \leq 0.01$. (c) RMS cells were transiently transfected with siRNA against NOXA or non-targeting control siRNA and were treated for $24 \mathrm{~h}(\mathrm{RH} 30)$ and $48 \mathrm{~h}(\mathrm{RD})$ after knockdown with $1 \mu \mathrm{M}$ AUR and $1 \mu \mathrm{M}$ BSO or ERA (RH30: $1 \mu \mathrm{M}, \mathrm{RD}: 2 \mu \mathrm{M})$. Cell death was determined by PI staining using flow cytometry. Mean and S.D. of at least three independent experiments carried out in triplicate are shown; ${ }^{*} P \leq 0.05,{ }^{* \star} P \leq 0.01$ 
a

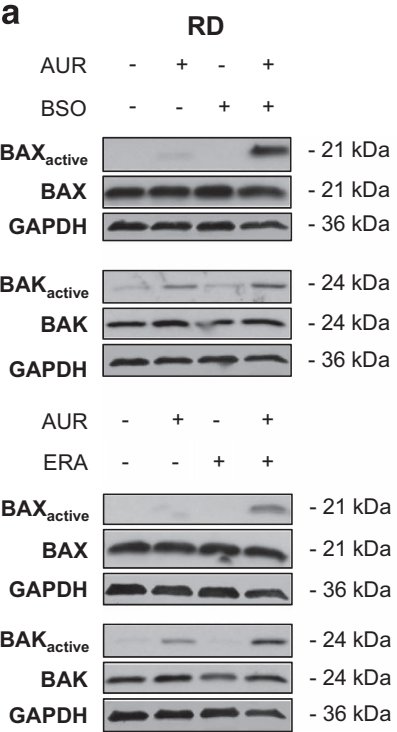

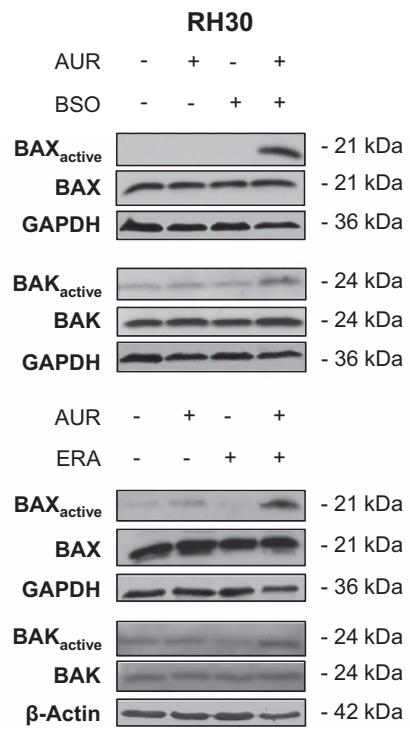

b
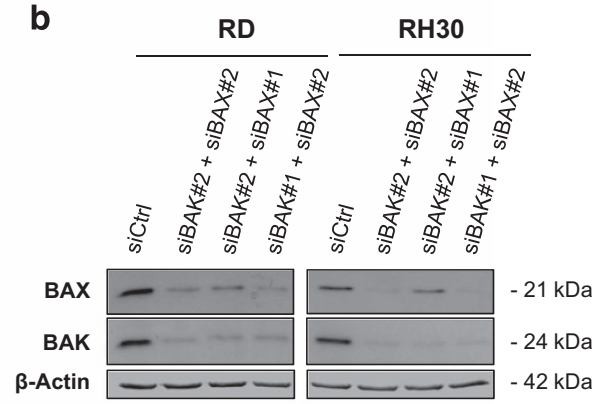

C

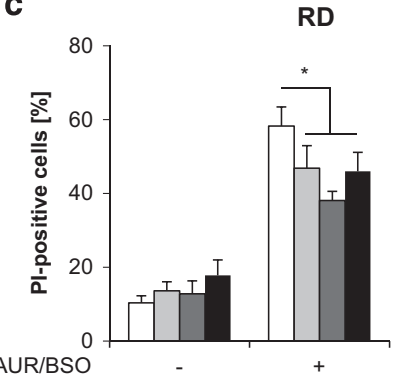

AUR/BSO

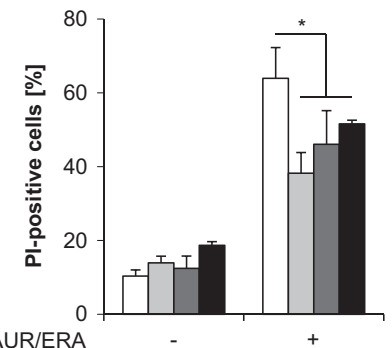

d

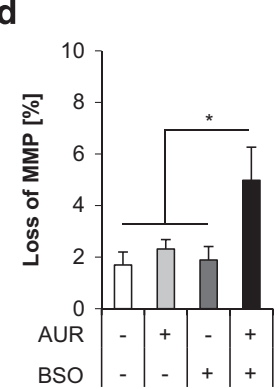

RD

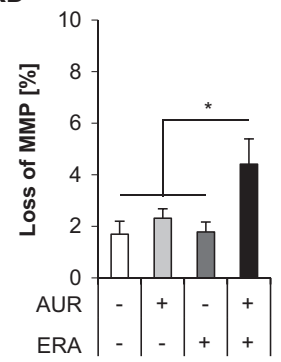

口 siCtrl

$\square$ SiBAK\#2+ SIBAX\#2

- siBAK\#2 + siBAX\#1

- siBAK\#1 + siBAX\#2

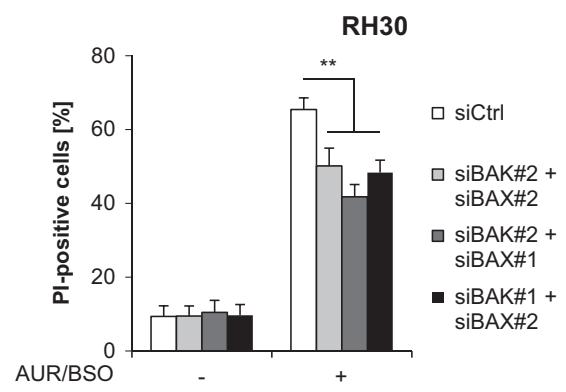

asiCtrl

口SiBAK\#2+ SiBAX\#2

- $S$ SBAK\#2 + siBAX\#1

- siBAK\#1 + siBAX\#2
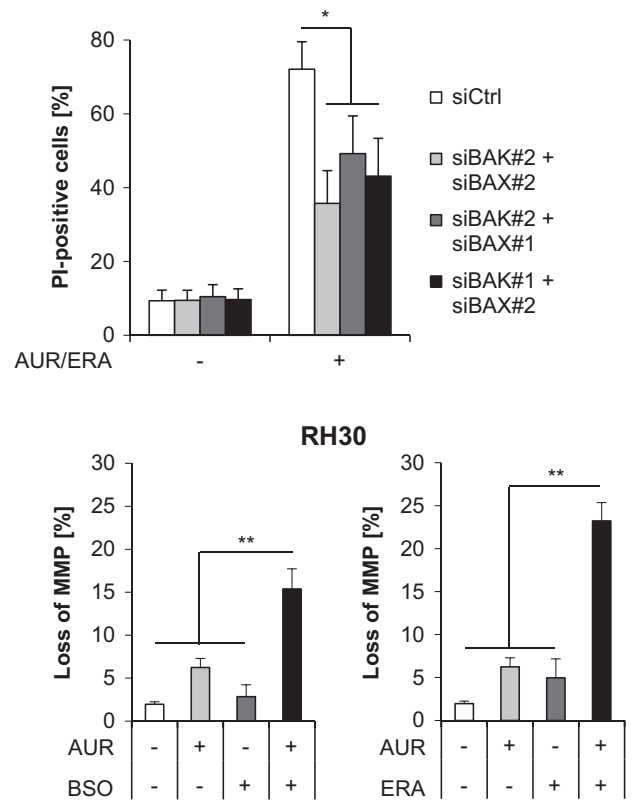

with BSO or ERA significantly decreased TrxR activity (Figure 7a). As both BSO and ERA are known to cause GSH depletion, ${ }^{13,41}$ we next monitored cellular GSH levels. As expected, BSO or ERA alone significantly reduced GSH levels (Figure 7b). Of note, treatment with AUR alone increased GSH levels (Figure 7b), in line with the described compensatory upregulation of the GSH synthesis pathway upon TrxR deficiency. ${ }^{22}$ Importantly, the addition of BSO or ERA abolished this AUR-stimulated increase in GSH levels, leading to reduced GSH levels in cotreated cells (Figure 7b). This shows that BSO or ERA counteract the AUR-stimulated increase in GSH levels. 
Figure 5 AUR/BSO or AUR/ERA cotreatment triggers BAX/BAK activation and loss of MMP. (a) RMS cells were treated for $15 \mathrm{~h}$ (RH30) and $18 \mathrm{~h}$ (RD) with $1 \mu \mathrm{M}$ AUR and/or $1 \mu \mathrm{M}$ BSO and/or ERA (RH30: $1 \mu \mathrm{M}, \mathrm{RD}: 2 \mu \mathrm{M})$. BAX/BAK activation was assessed by immunoprecipitation using a conformation-specific anti-BAX or anti-BAK antibody and expression of BAX and BAK was analyzed by Western blotting, GAPDH and $\beta$-actin served as loading control. (b) RMS cells were transiently transfected with siRNA against BAX and BAK or non-targeting control siRNA. Protein expression of BAX and BAK was assessed by Western blotting $48 \mathrm{~h}$ after knockdown. $\beta$-actin served as loading control. (c) RMS cells were transiently transfected with siRNA against BAX and BAK or non-targeting control siRNA and were treated for $24 \mathrm{~h}(\mathrm{RH} 30)$ and $48 \mathrm{~h}(\mathrm{RD})$ after knockdown with $1 \mu \mathrm{M}$ AUR and $1 \mu \mathrm{M}$ BSO or ERA (RH30: $1 \mu \mathrm{M}, \mathrm{RD}: 2 \mu \mathrm{M})$. Cell death was determined by PI staining using flow cytometry. Mean and S.D. of at least three independent experiments carried out in triplicate are shown; ${ }^{*} P \leq 0.05,{ }^{* *} P \leq 0.01$. (d) RMS cells were treated for $15 \mathrm{~h}$ (RH30) and $18 \mathrm{~h}$ (RD) with $1 \mu \mathrm{M}$ AUR and/or $1 \mu \mathrm{M} \mathrm{BSO}$ and/or ERA (RH30: $1 \mu \mathrm{M}$, RD: $2 \mu \mathrm{M}$ ). Loss of MMP was determined by FACS analysis of the viable cell population using the fluorescent dye TMRM. Mean and S.D. of at least three independent experiments carried out in triplicate are shown; ${ }^{*} P \leq 0.05,{ }^{*} P \leq 0.01$

Re-supply of GSH rescues AUR/BSO- or AUR/ERAinduced proteasome inhibition, NOXA accumulation and cell death. The observed decrease of GSH levels in AUR/BSO- or AUR/ERA-cotreated cells may increase AUR's cytotoxicity, as thiol groups have been described to block the activity of AUR ${ }^{42,43}$ To further investigate the relevance of the cellular GSH pool in regulating AUR's cytotoxicity, we tested GSH as thiol donor. Importantly, the addition of $\mathrm{GSH}$ completely abolished both AUR/BSO- and AUR/ERA-induced ROS production and cell death (Figures $8 a$ and $b$ ). Of note, GSH prevented accumulation of ubiquitinated proteins, as well as accumulation of NOXA upon AUR/BSO or AUR/ERA cotreatment (Figures $8 \mathrm{c}$ and d). Similar to $\mathrm{GSH}$, addition of NAC, a precursor of GSH and thiol-containing antioxidant, abolished both AUR/BSO- and AUR/ERA-stimulated accumulation of ubiquitinated proteins and NOXA (Figures $8 \mathrm{e}$ and f). In contrast, the non-thiol-containing antioxidant $a$-Toc reduced the accumulation of ubiquitinated proteins and NOXA in both AUR/ERA-treated cell lines and in AUR/BSOtreated $\mathrm{RH} 30$ cells, but not in AUR/BSO-treated RD cells (Figures $8 e$ and $f$ ). These findings are in line with the differential ability of NAC and $\alpha$-Toc to protect RMS cells from AUR/ERA- or AUR/BSO-induced cell death (Figure 2b). Together this set of experiments shows that re-supply of GSH rescues AUR/BSO- or AUR/ERA-induced proteasome inhibition, NOXA accumulation and cell death. This underscores that depletion of cellular GSH levels has an important role in unleashing AUR-induced cell death.

\section{Discussion}

As oxidative stress has recently been identified as a pathway of therapeutic relevance in RMS, ${ }^{31}$ we tested in this study whether concomitant pharmacological inhibition of the two main antioxidant pathways, that is, the TRX and the GSH synthesis pathway, may constitute a new treatment strategy for RMS. Here, we discovered that GSH-depleting agents, that is, BSO or ERA, synergize with AUR to induce cell death in RMS cells. This synergism is confirmed by calculation of $\mathrm{Cl}$. The potency of this combination is emphasized by data showing that AUR/BSO or AUR/ERA cotreatment also suppresses long-term clonogenic survival.

Importantly, we identify the BSO- or ERA-stimulated depletion of the cellular GSH pool rather than changes in ROS levels as a relevant mechanism sensitizing cells for AURinduced cell death (Figure 9). Several lines of evidence support this conclusion. First, BSO or ERA counteract the AUR-stimulated upregulation of GSH levels, resulting in GSH depletion. The increase in GSH levels by AUR points to a compensatory upregulation of the GSH synthesis pathway upon inhibition of the TRX system, in line with the reported redundancy between the GSH and the TRX systems. ${ }^{21-25}$ Second, replenishing the cellular GSH pool by adding GSH or NAC, a precursor of GSH, completely blocks AUR/BSO- or AUR/ERA-induced cell death. Third, only thiol-containing antioxidants, but not ROS scavengers without thiol groups consistently abrogate AUR/BSO- or AUR/ERA-induced cell death in both RMS cell lines. Changes in intracellular GSH levels likely affect AUR's cytotoxicity, as thiol groups have been described to inactivate AUR via reaction with its gold ion. ${ }^{42,43}$ This implies that GSH depletion by BSO or ERA can unleash the cytotoxicity of AUR.

Of note, in line with the recently described ability of AUR to inhibit proteasome-associated DUBs, ${ }^{30}$ we provide evidence showing that proteasome inhibition is important for AUR/BSOor AUR/ERA-induced cell death. This conclusion is supported by our data showing that AUR/BSO or AUR/ERA cotreatment leads to proteasome inhibition, as indicated by the accumulation of ubiquitinated proteins and by enhanced ubiquitination of short-lived proteins such as NOXA and MCL-1. Also, the addition of thiol-containing compounds that block AUR/BSOor AUR/ERA-induced cell death abolishes proteasome inhibition by AUR/BSO or AUR/ERA, as well as subsequent upregulation of short-lived proteins such as NOXA.

We identify NOXA as an important mediator of AUR/BSO- or AUR/ERA-induced cell death that accumulates in parallel to AUR/BSO- or AUR/ERA-mediated proteasome inhibition. NOXA is a short-lived proapoptotic protein of the BCL-2 family and a known target of the proteasome. ${ }^{34}$ Knockdown experiments showing that NOXA silencing protects from AUR/BSO or AUR/ERA cotreatment indeed confirm that NOXA contributes to AUR/BSO- or AUR/ERA-induced cell death. Consistently, the increase in NOXA levels resulted in enhanced binding and consequently in neutralization of MCL-1 upon AUR/BSO or AUR/ERA cotreatment. In addition to caspases, also caspase-independent mechanisms are likely involved in mediating AUR/BSO- or AUR/ERA-induced cell death, as the pan-caspase inhibitor zVAD.fmk failed to rescue cell death, as the pan-caspase inhibitor zvad.fmk failed to rescue AUR/BSO- or AUR/ERA-induced cell death despite blocking caspase activation. For example, in RH30 cells, ferroptotic signaling pathways may partially contribute to AUR/ BSO- and AUR/ERA-induced cell death. Also, we recently identified caspase-independent mechanisms, in this case involving endonuclease $\mathrm{G}$, during vincristine and Polo-likekinase (PLK) 1 inhibitor-induced apoptosis in RMS cells. ${ }^{39}$

Although we show that proteasome inhibition rather than ROS generation consistently accounts for both AUR/BSO- 

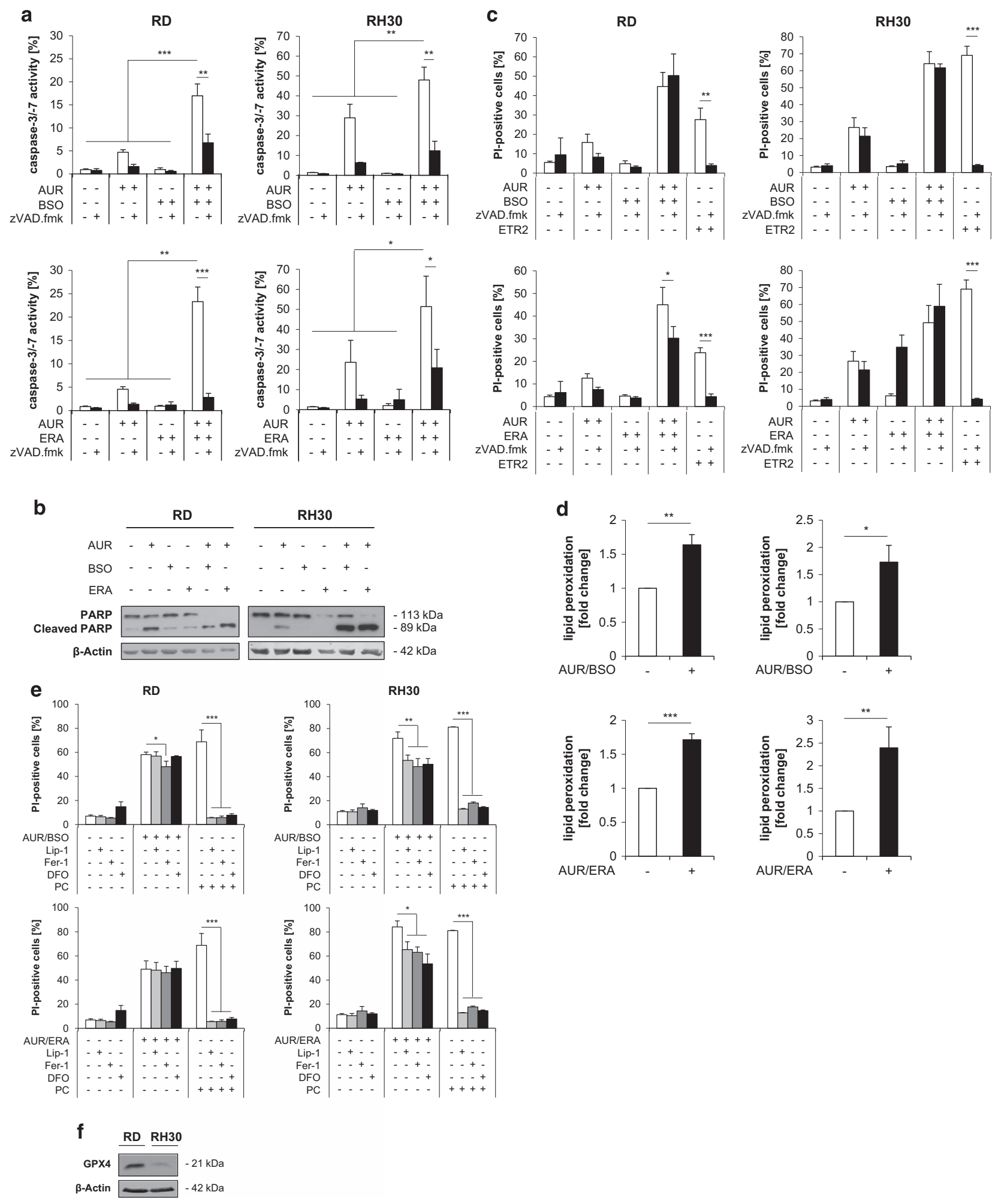

and AUR/ERA-induced cell death, ROS may contribute to some extent to the induction of cell death, especially in the case of AUR/ERA cotreatment. Upon AUR/ERA cotreatment, ROS production may further enhance proteasome inhibition, as the non-thiol ROS scavenger $a$-Toc reduces AUR/ERA- triggered proteasome inhibition and NOXA accumulation in addition to its protection from cell death. Indeed, ROS have previously been described to inhibit the proteasome. ${ }^{44,45}$

Our findings have important implications for the development of novel strategies for the treatment of RMS, as AUR or 
Figure 6 AUR/BSO- or AUR/ERA-induced cell death is largely caspase-independent. (a) RMS cells were treated for $24 \mathrm{~h}(\mathrm{RH} 30)$ and $48 \mathrm{~h}(\mathrm{RD})$ with $1 \mu \mathrm{M} \mathrm{AUR}$ and/or $1 \mu \mathrm{M}$ BSO and/or ERA (RH30: $1 \mu \mathrm{M}, \mathrm{RD}: 2 \mu \mathrm{M}$ ). Activation of caspase-3 or -7 was detected by fluorescence microscopy using CellEvent Caspase-3/7 Green Detection Reagent. Staining of the cells with Hoechst served as cell count control. Mean and S.D. of at least three experiments performed in triplicate are shown; ${ }^{*} P \leq 0.05,{ }^{* \star} P \leq 0.01,{ }^{* \star \star} P \leq 0.001$. (b) Cells were treated for $24 \mathrm{~h}$ (RH30) and $48 \mathrm{~h}$ (RD) with $1 \mu \mathrm{M}$ AUR and/or $1 \mu \mathrm{M} \mathrm{BSO}$ and/or ERA (RH30: $1 \mu \mathrm{M}, \mathrm{RD}: 2 \mu \mathrm{M})$. Protein expression of PARP was assessed by Western blotting. $\beta$-Actin served as loading control. (c) Cells were treated for $24 \mathrm{~h}$ (RH30) and $48 \mathrm{~h}$ (RD) with $1 \mu \mathrm{M}$ AUR and/or $1 \mu \mathrm{M}$ BSO and/or ERA (RH30: $1 \mu \mathrm{M}, \mathrm{RD}: 2 \mu \mathrm{M}$ ) in the presence and absence of $50 \mu \mathrm{M}$ zVAD.fmk, which was added $1 \mathrm{~h}$ before treatment. $2 \mu \mathrm{g} / \mathrm{ml}$ TRAlL receptor-2 agonistic antibody ETR2 served as positive control for caspase-dependent cell death. Cell death was determined by PI staining using flow cytometry. Mean and S.D. of at least three independent experiments performed in triplicate are shown; ${ }^{*} P \leq 0.05,{ }^{* *} P \leq 0.01,{ }^{* * *} P \leq 0.001$. (d) RMS cells were treated for $15 \mathrm{~h}(\mathrm{RH} 30)$ and $18 \mathrm{~h}$ (RD) with $1 \mu \mathrm{M}$ AUR and $1 \mu \mathrm{M}$ BSO or ERA (RH30: $\left.1 \mu \mathrm{M}, \mathrm{RD}: 2 \mu \mathrm{M}\right)$. Lipid peroxidation was determined by FACS analysis of the viable cell population using the fluorescent dye BODIPY and is shown as $x$-fold change compared with control. Mean and S.D. of at least three independent experiments carried out in triplicate are shown; ${ }^{*} P \leq 0.05,{ }^{* \star} P \leq 0.01,{ }^{* \star \star} P \leq 0.001$ (e) RMS cells were treated for $24 \mathrm{~h}(\mathrm{RH} 30)$ or $48 \mathrm{~h}(\mathrm{RD})$ with $1 \mu \mathrm{M}$ AUR and/or $1 \mu \mathrm{M} \mathrm{BSO}$ and/or ERA (RH30: $1 \mu \mathrm{M}, \mathrm{RD}: 2 \mu \mathrm{M}$ ) or for $24 \mathrm{~h}$ with $3 \mu \mathrm{M}$ ERA (RH30) or $5 \mu \mathrm{M}$ ERA (RD), which served as positive control (PC), in the presence and absence of $50 \mathrm{nM} \mathrm{Lip}-1,5 \mu \mathrm{M}$ Fer-1 or $25 \mu \mathrm{M} \mathrm{DFO}$, which were added $1 \mathrm{~h}$ before treatment. Cell death was determined by PI staining using flow cytometry. Mean and S.D. of at least three independent experiments carried out in triplicate are shown; ${ }^{*} P \leq 0.05,{ }^{* \star} P \leq 0.01,{ }^{\star \star *} P \leq 0.001$. (f) Basal protein expression of GPX4 was assessed by Western blotting. $\beta$-Actin served as loading control

BSO have already been tested in clinical trials, although not in combination. For example, AUR is currently being used in clinical trials for the therapy of recurrent epithelial ovarian, primary peritoneal and fallopian tube cancer ${ }^{46}$ and has been investigated in clinical trials in chronic lymphocytic leukemia. ${ }^{47}$ AUR-based combination therapy that allows dose reduction by exploiting synergistic drug interactions may reduce the risk of side effects that have been described for AUR. ${ }^{48} \mathrm{BSO}$ proved to be well tolerated in clinical trials, for example, in combination with melphalan. ${ }^{49}$ The relevance of GSH-depleting strategies for the treatment of RMS is emphasized by a recent report showing that RMS cells harbor elevated GSH levels compared with normal myocytes. ${ }^{32}$ By demonstrating that GSHdepleting agents at subtoxic concentrations synergistically enhance the antitumor activity of AUR, whereas neither GSH depletion nor AUR alone are sufficient to trigger cell death, our study highlights new options targeting cellular redox homeostasis for the treatment of RMS.

\section{Materials and Methods \\ Cell culture and chemicals. Human RMS cell lines were obtained from the American Type Culture Collection (Manassas, VA, USA) or from the Deutsche Sammlung von Mikroorganismen und Zellkulturen GmbH (Braunschweig, Ger- many). Cells were cultured in RPMI-1640 or DMEM GlutaMAX medium (Life Technologies, Inc., Eggenstein, Germany) supplemented with $10 \%$ fetal calf serum, $1 \%$ penicillin/streptomycin and $1 \mathrm{mM}$ sodium pyruvate (Invitrogen, Karlsruhe, Germany). Chemicals were purchased from Sigma-Aldrich (Steinheim, Germany). Reduced GSH was purchased from Carl Roth (Karlsruhe, Germany). The caspase inhibitor zVAD.fmk was purchased from Bachem (Heidelberg, Germany).}

Determination of cell death and clonogenic growth. Cell death was assessed by analyzing plasma membrane permeability with propidium iodide (PI) staining as described previously using flow cytometry ${ }^{50}$ (FACS Canto II, BD Biosciences, Heidelberg, Germany). To determine colony formation, cells were seeded in a 24-well tissue culture plate, allowed to settle overnight and treated with AUR, BSO, ERA or the combinations for $9 \mathrm{~h}(\mathrm{RD})$ or $4 \mathrm{~h}(\mathrm{RH} 30)$. Afterward cells were trypsinized, counted and 200 cells were seeded in a six-well tissue culture plate. Colonies were stained after 10-12 days without medium change with crystal violet solution. Colonies were counted and the percentage of colonies relative to solvent-treated controls was calculated.

Caspase activity assay. To determine caspase activation, the CellEvent Caspase-3/7 Green Detection Reagent from Thermo Fisher Scientific (Darmstadt, Germany) was used following the instructor's manual. In parallel, cells were stained with $1 \mu \mathrm{g} / \mu \mathrm{l}$ Hoechst-Dye (Sigma-Aldrich) and measured by fluorescence microscopy (ImageXpress Mikro XLS, Sunnyvale, CA, USA) with automated analysis using MetaXpress Software (Molecular Devices).
Determination of ROS production, lipid peroxidation, intracellular GSH levels and TrxR activity. To analyze ROS production or lipid peroxidation, medium was discarded, cells were stained for $30 \mathrm{~min}$ at $37^{\circ} \mathrm{C}$ with $5 \mu \mathrm{M} \mathrm{CM}-\mathrm{H}_{2}$ DCFDA (Invitrogen) for ROS production or $5 \mu \mathrm{M}$ BODIPY (Life Technologies, Inc.) for lipid peroxidation. Subsequently, they were trypsinized, centrifuged for $10 \mathrm{~min}$ at $4{ }^{\circ} \mathrm{C}$ and supernatant was discarded. Cells were resuspended in white RPMI (Life Technologies, Inc.) and immediately analyzed by flow cytometry. To determine GSH levels in the cells the GSH/GSSG-Glo assay (Promega, Madison, WI, USA) was used following the instructor's manual. In parallel, cells were stained with $1 \mu \mathrm{g} / \mu$ l Hoechst-Dye (Sigma-Aldrich) and measured by fluorescence microscopy (ImageXpress Mikro XLS) with automated analysis using MetaXpress Software (Molecular Devices). Luciferase signal was normalized to 10000 cells. TrxR activity was measured with the Thioredoxin Reductase Assay Kit Colorimetric (Abcam, Cambridge, UK) following the instructor's manual. Protein content of the lysates was determined using the Pierce BCA Protein Assay Kit (Thermo Fisher Scientific) and $80 \mu \mathrm{g}$ of protein were used for each analysis. Negative data appearing after measurement or during analysis were defined as zero, meaning no TrxR activity.

RNA interference. For transient knockdown by siRNA, cells were reversely transfected with $10 \mathrm{nM}$ or $20 \mathrm{nM}$ SilencerSelect siRNA (Life Technologies, Inc.), that is, control siRNA (4390842 siCtrl) or targeting siRNA (s10709 siNoxa \#1, s10710 siNoxa \#2) for NOXA; (s1880 siBAK\#1, s1881 siBAK\#2) for BAK; (s1889 siBAX\#1, s1890 siBAX\#2) for BAX.

Western blot analysis. Western blot analysis was performed as described previously, ${ }^{51}$ using the following antibodies: mouse anti-GPX4 (R\&D Systems, Wiesbaden, Germany), rabbit anti-NQ01 and mouse IgG1 anti-ubiquitin (P4D1) (Santa Cruz Biotechnology, Santa Cruz, CA, USA), rabbit anti-BAX (Millipore, Darmstadt, Germany), mouse anti-NOXA (Alexis Biochemicals, Grünberg, Germany), rabbit anti-BAK (BD Biosciences), mouse anti-PARP (Cell Signaling, Beverly, MA, USA), rabbit anti-MCL-1 (Stressgen, Victoria, BC, Canada), mouse anti-GAPDH (HyTest, Turku, Finland) or mouse anti- $\beta$-Actin (Sigma-Aldrich). Goat anti-mouse and goat anti-rabbit with conjugated horseradish peroxidase (Santa Cruz Biotechnology) were used for enhanced chemiluminescence (Amersham Biosciences, Freiburg, Germany) detection or infrared dye-labeled secondary antibodies were used in combination with an infrared imaging system (Odysee Imaging System, LI-COR Biosciences, Bad Homburg, Germany).

Immunoprecipitation. Immunoprecipitation of active BAX and BAK was performed as previously described. ${ }^{52}$ Briefly, cells were lysed in CHAPS lysis buffer (10 nmol// HEPES, pH 7.4; $150 \mathrm{nmol} / / \mathrm{NaCl} ; 1 \%$ CHAPS). 500-1000 $\mu$ g protein was immunoprecipitated and incubated overnight at $4{ }^{\circ} \mathrm{C}$ with $2 \mu \mathrm{g} / \mathrm{ml}$ mouse anti-BAK antibody (Ab-1; Merck Millipore, Billerica, MA, USA) or anti-BAX antibody (6A7, Sigma-Aldrich) and $10 \mu \mathrm{l}$ pan-mouse IgG Dynabeads (Life technologies, Inc.), washed with CHAPS lysis buffer and analyzed by western blotting using rabbit antiBAK antibody (BD Bioscience) or anti-BAX antibody (Merck, Darmstadt, Germany). Immunoprecipitation of MCL-1 was performed in $500 \mu$ l lysates containing up to $1000 \mu \mathrm{g}$ proteins, which were incubated overnight at $4{ }^{\circ} \mathrm{C}$ with $2 \mu \mathrm{g} / \mathrm{ml}$ mouse antiMCL-1 antibody (BD Biosciences) and $10 \mu \mathrm{l}$ pan-mouse IgG Dynabeads or Protein $G$ Dynabeads (Life Technologies, Inc.) and washed with CHAPS buffer. The precipitate was analyzed for interaction with NOXA by Western blotting using rabbit 
a
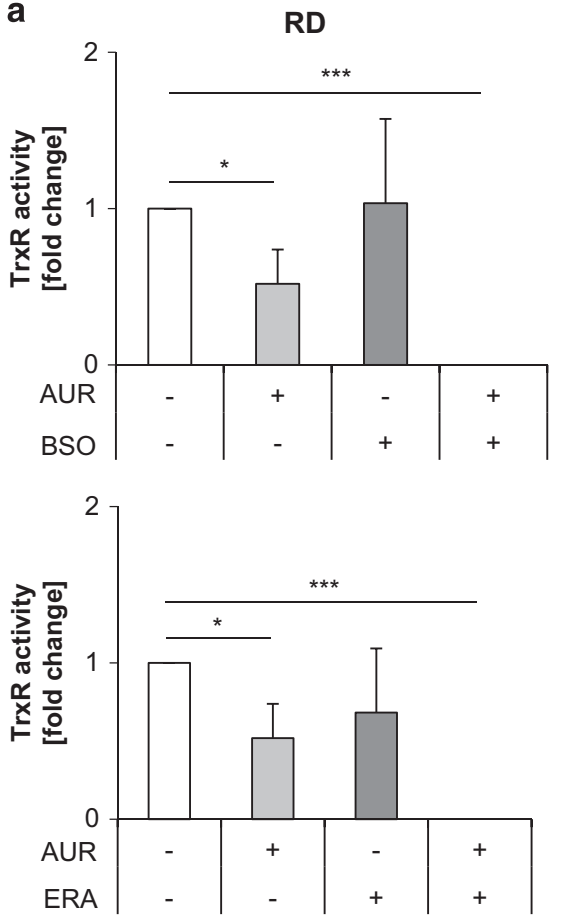

b
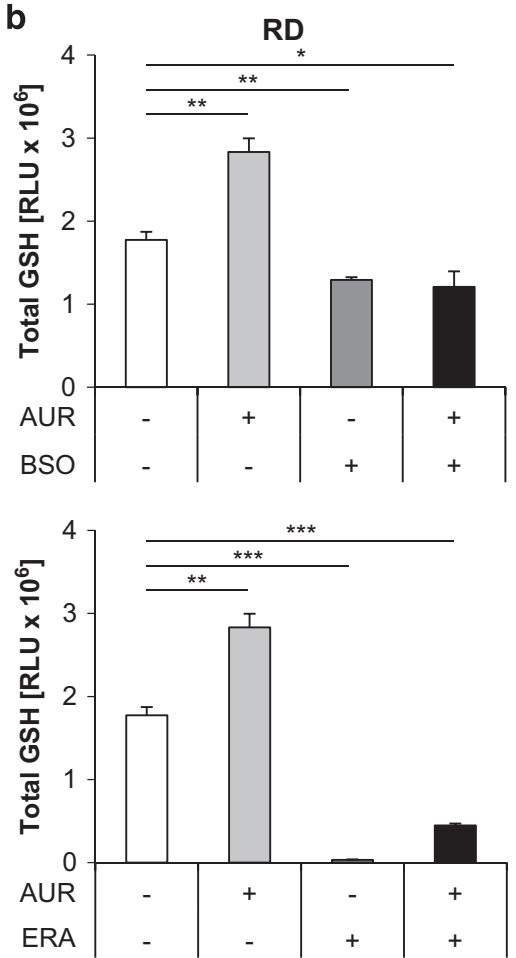

RH30
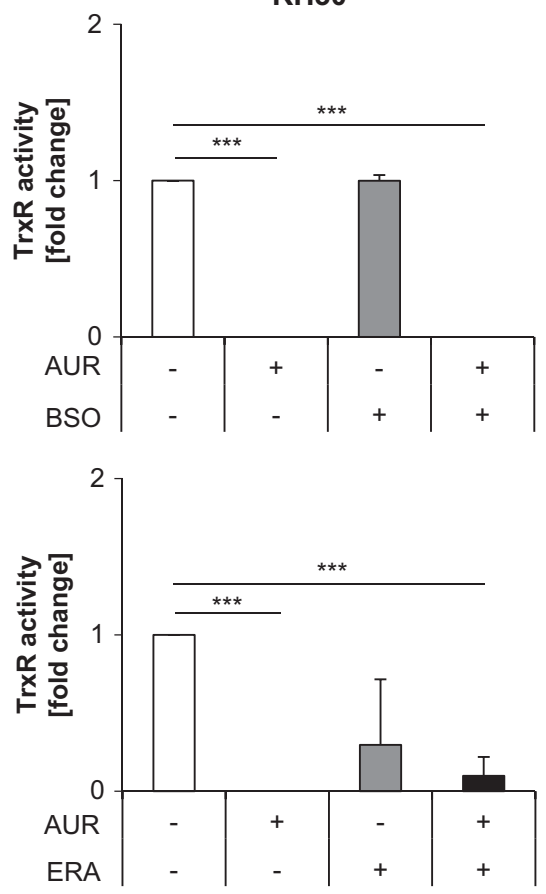

RH30
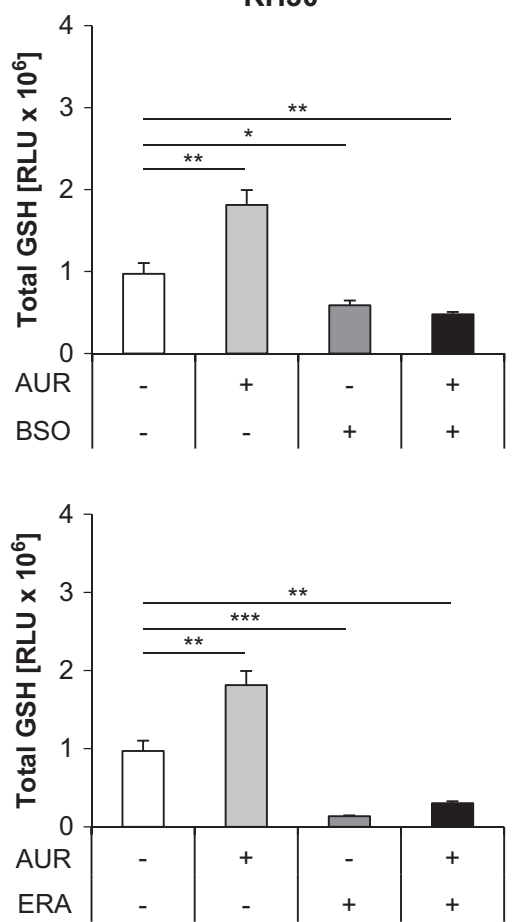

Figure 7 BSO or ERA counteract the AUR-stimulated increase in GSH levels. (a and $\mathbf{b})$ RMS cells were treated for $15 \mathrm{~h}(\mathrm{RH} 30)$ and $18 \mathrm{~h}$ (RD) with $1 \mu \mathrm{M}$ AUR and/or $1 \mu \mathrm{M}$ $\mathrm{BSO}$ and/or ERA (RH30: $1 \mu \mathrm{M}, \mathrm{RD}: 2 \mu \mathrm{M}$ ). (a) TrxR activity was determined using the TrxR assay kit colorimetric from Abcam following the instructor's manual. In all, $80 \mu \mathrm{g}$ of protein were used for each analysis. Activity is shown as $x$-fold expression compared with control. Mean and S.D. of three independent experiments performed in triplicate are shown; ${ }^{*} P \leq 0.05,{ }^{* * *} P \leq 0.001$. (b) The intracellular amount of total GSH was determined using the GSH/GSSG-Glo Assay from Promega following the manufacturer's information. Luciferase signal (RLU) was normalized to 10000 cells. Mean and S.D. of three independent experiments performed in triplicate are shown; ${ }^{*} P \leq 0.05,{ }^{* *} P \leq 0.01$, ${ }^{* \star *} P \leq 0.001$ 
a
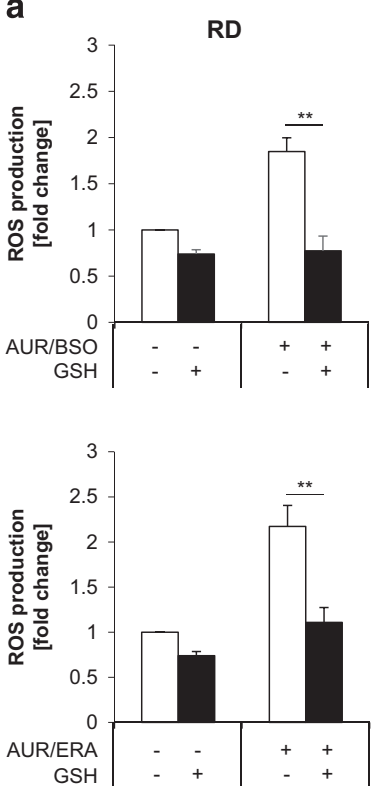

b
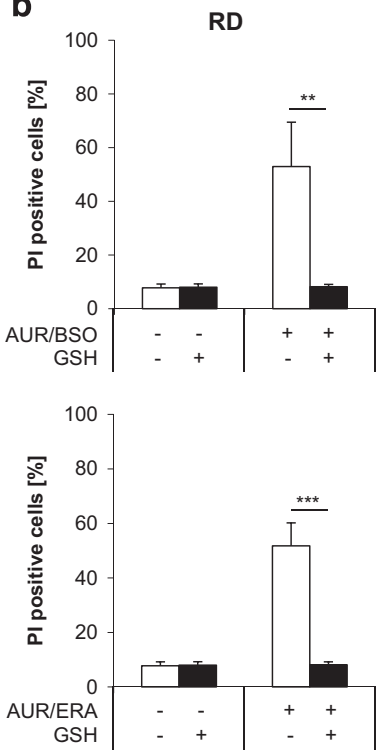

RH30
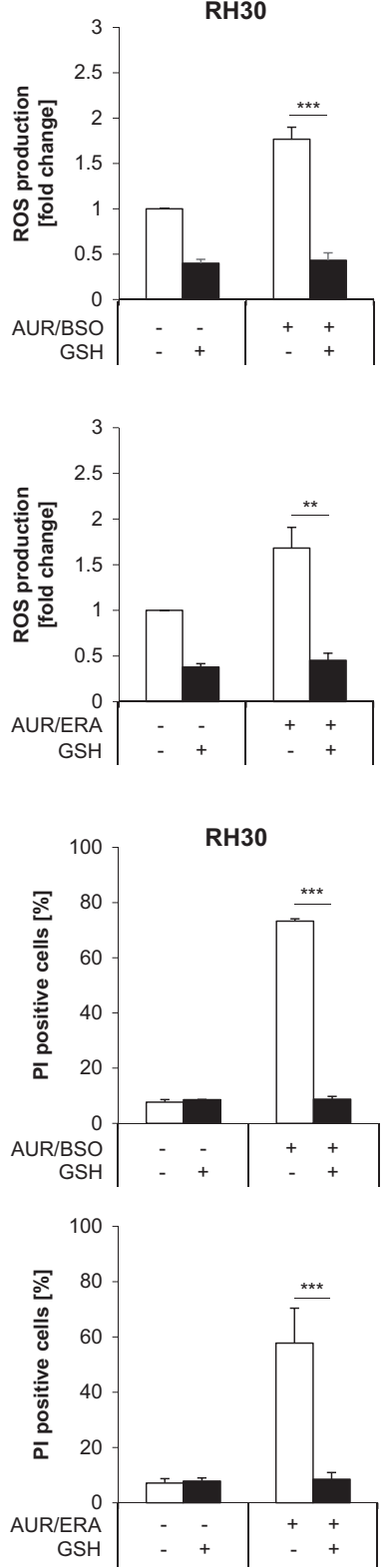

C

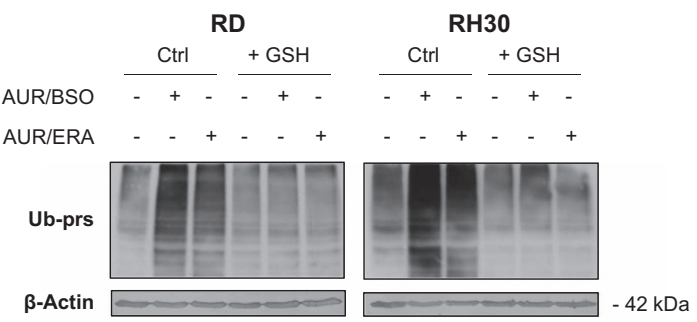

d
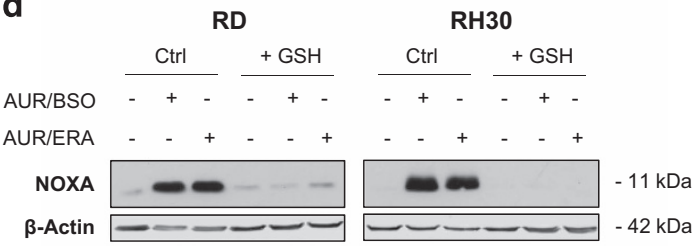

e

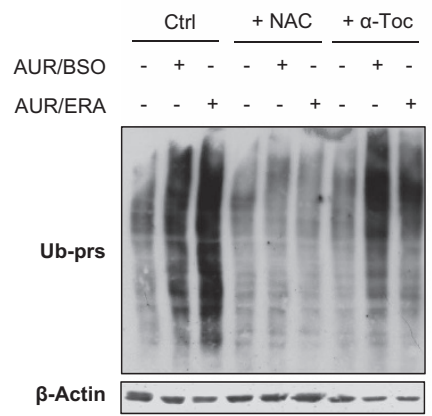

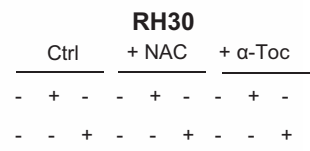

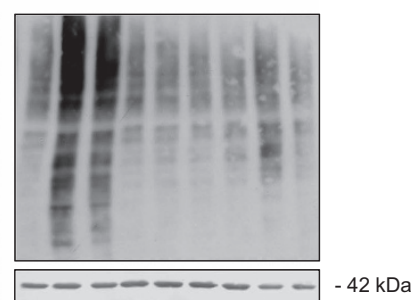

f

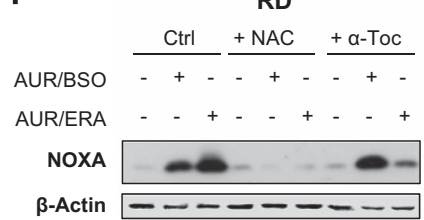

RH30

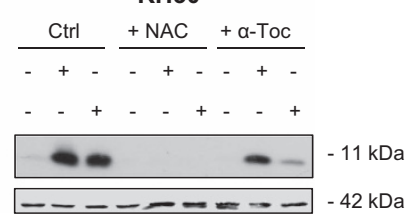

Figure 8 Re-supply of GSH rescues AUR/BSO- or AUR/ERA-induced proteasome inhibition, NOXA accumulation and cell death. (a) RMS cells were treated for $15 \mathrm{~h}$ (RH30) and $18 \mathrm{~h}(\mathrm{RD})$ with $1 \mu \mathrm{M}$ AUR and $1 \mu \mathrm{M}$ BSO or ERA (RH30: $1 \mu \mathrm{M}, \mathrm{RD}: 2 \mu \mathrm{M})$ in the presence and absence of $2.5 \mathrm{mM}$ reduced GSH, which was added $1 \mathrm{~h}$ before treatment. ROS production was determined by FACS analysis of the viable cell population using the fluorescent dye CM-H2DCFDA and is shown as $x$-fold ROS production compared with control. Mean and S.D. of at least three independent experiments performed in triplicate are shown; ${ }^{* *} P \leq 0.01,{ }^{* * \star} P \leq 0.001$. (b) RMS cells were treated for $24 \mathrm{~h}$ (RH30) and $48 \mathrm{~h}$ (RD) with $1 \mu \mathrm{M}$ AUR and $1 \mu \mathrm{M} \mathrm{BSO}$ or ERA (RH30: $1 \mu \mathrm{M}, \mathrm{RD}: 2 \mu \mathrm{M})$ in the presence and absence of $2.5 \mathrm{mM}$ reduced GSH, which was added $1 \mathrm{~h}$ before treatment. Cell death was determined by PI staining using flow cytometry. Mean and S.D. of at least three independent experiments are shown; ${ }^{* *} P \leq 0.01,{ }^{* * *} P \leq 0.001$. (c and d) Cells were treated for $18 \mathrm{~h}(\mathrm{RH} 30)$ and $24 \mathrm{~h}(\mathrm{RD})$ with $1 \mu \mathrm{M}$ AUR and $1 \mu \mathrm{M}$ BSO or ERA (RH30: $1 \mu \mathrm{M}, \mathrm{RD}: 2 \mu \mathrm{M})$ in the presence and absence of $2.5 \mathrm{mM}$ reduced GSH, which was added $1 \mathrm{~h}$ before treatment. Protein expression of ubiquitinated proteins (Ub-prs) and NOXA were determined through Western blotting. $\beta$-Actin served as loading control. (e and $\mathbf{f})$ Cells were treated for $18 \mathrm{~h}$ (RH30) and $24 \mathrm{~h}(\mathrm{RD})$ with $1 \mu \mathrm{M}$ AUR and $1 \mu \mathrm{M} \mathrm{BSO}$ or ERA (RH30: $1 \mu \mathrm{M}, \mathrm{RD}: 2 \mu \mathrm{M}$ ) in the presence and absence of $10 \mathrm{mM} \mathrm{NAC}$ or $100 \mu \mathrm{M} \alpha$-Toc, which were added $1 \mathrm{~h}$ before treatment. Protein expression of ubiquitinated proteins (Ub-prs) and NOXA were determined through Western blotting. $\beta$-Actin served as loading control

anti-MCL-1 antibody (ENZO, Lausen, Switzerland) and mouse anti-NOXA antibody (Alexis Biochemicals, Grünberg, Germany).

TUBE pull-down assay. TUBE pull-down assay was performed as previously described. ${ }^{35}$ Cells were lysed in buffer $(50 \mathrm{mM} \mathrm{NaCl}, 20 \mathrm{mM}$ Tris pH 7,5, 1\% NP40, $5 \mathrm{mM}$ EDTA, $10 \%$ glycerol) supplemented with a protease inhibitor cocktail tablet (Roche Diagnostics, Mannheim, Germany) for $20 \mathrm{~min}$ on ice. In all, $1000 \mu \mathrm{g}$ of protein were incubated overnight at $4^{\circ} \mathrm{C}$ with $50 \mu \mathrm{l}$ GSH-agarose beads (Sigma-Aldrich) linked to GST-TUBE. Afterward beads were washed with buffer. The precipitate was analyzed for ubiquitin expression by Western blotting using mouse IgG1 anti-ubiquitin (P4D1) (Santa Cruz Biotechnology) antibody and for interaction with NOXA and MCL-1 by Western blotting using rabbit anti-MCL-1 antibody (ENZO), and mouse anti-NOXA antibody (ENZO). To verify the protein amount per lane, the membrane was stained with Ponceau S (AppliChem GmbH, Darmstadt, Germany). 


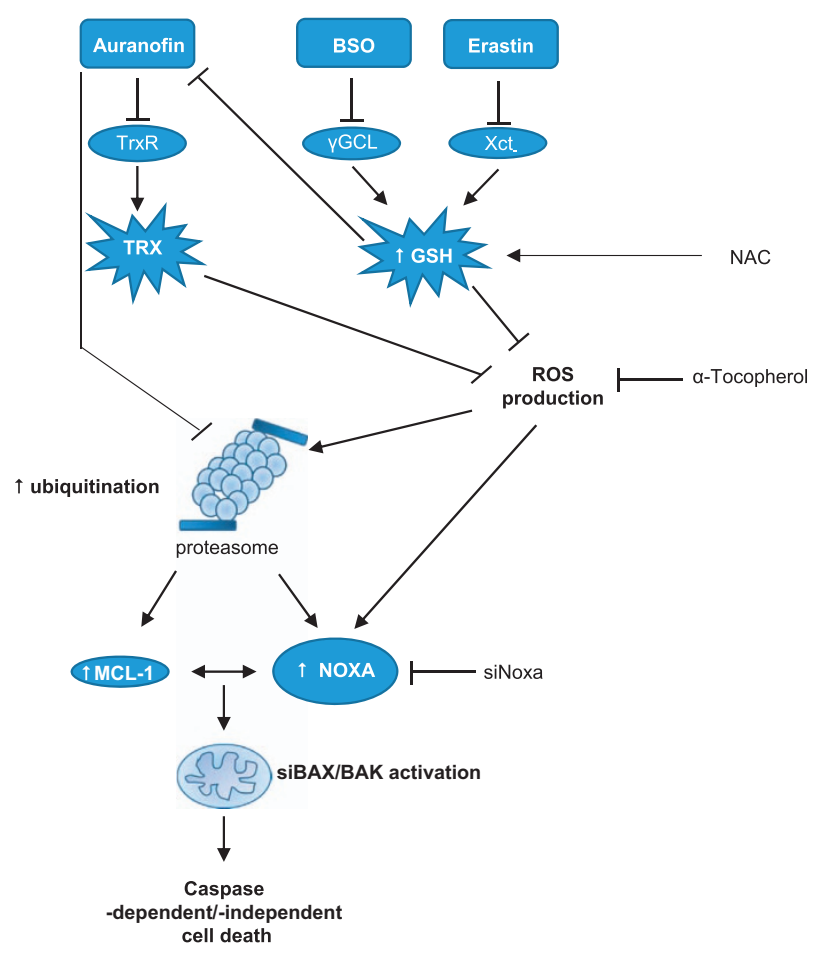

Figure 9 Scheme of AUR/BSO- or AUR/ERA-triggered synergistic cell death. AUR inhibits TrxR, which leads to upregulation of GSH, inhibiting AUR. ERA or BSO cause depletion of GSH levels, thereby counteracting the AUR-mediated upregulation of GSH and increasing AUR's cytotoxic activity. This leads to proteasome inhibition and subsequently to accumulation of ubiquitinated NOXA and MCL-1, followed by activation of BAX/BAK and caspases. See text for more details

Determination of MMP. To determine MMP, cells were incubated with TMRM (50 nM; Invitrogen) for 30 min at $37^{\circ} \mathrm{C}$ and immediately analyzed by flow cytometry.

Quantitative real-time PCR. Total RNA was isolated using pegGOLD Total RNA kit from Peqlab Biotechnologie GmbH (Erlangen, Germany) according to the manufacturer's instructions. A total of $1 \mu \mathrm{g}$ of RNA was used to synthesize the corresponding cDNA using RevertAid H Minus First Strand cDNA Synthesis Kit (MBI Fermentas GmbH, St. Leon-Rot, Germany). To quantify gene expression levels, SYBRGreen-based qRT-PCR was performed using the $7900 \mathrm{HT}$ fast real-time PCR system from Applied Biosystems (Darmstadt, Germany). Data were normalized on 28S-rRNA expression as reference gene. Primers are listed in Supplementary Table 2. Melting curves were plotted to verify the specificity of the amplified products. The relative expression of the target gene transcript and reference gene transcript was calculated as $\Delta \Delta$ ct. At least three independent experiments in duplicate were performed for each gene.

Statistical analysis and calculation of the $\mathrm{Cl}$ values. All results are shown as mean \pm S.D. Statistical significance was calculated by using Student's $t$-test (two-tailed, two sample, equal variance). $\mathrm{Cl}$ calculation was performed with CalcuSyn software (Biosoft, Cambridge, UK) with the $\mathrm{Cl}$ calculation method. Calculated $\mathrm{Cl}$ values were defined in the following way: $\mathrm{Cl}<0.9$ synergistic, $0.9-1.1$ additive and $\mathrm{Cl}>1.1$ antagonistic. $P$-values were interpreted as follows: ${ }^{*} P \leq 0.05$; ${ }^{* *} P \leq 0.01 ;{ }^{* \star *} P \leq 0.001$.

\section{Conflict of Interest}

The authors declare no conflict of interest.

Acknowledgements. We thank $\mathrm{C}$ Hugenberg for expert secretarial assistance. This work has been partially supported by grants from the DFG SFB815 (to SF), the BMBF (to SF), the European Union's Horizon 2020 research and innovation program under the Marie Sklodowska-Curie grant agreement No 675448 (to SF) and the Deutsche Krebshilfe (to SF and LG).

\section{Publisher's Note}

Springer Nature remains neutral with regard to jurisdictional claims in published maps and institutional affiliations.

1. Kramer S, Meadows AT, Jarrett $P$, Evans AE. Incidence of childhood cancer: experience of a decade in a population-based registry. J Natl Cancer Inst 1983; 70: 49-55.

2. Hayes-Jordan A, Andrassy R. Rhabdomyosarcoma in children. Curr Opin Pediatr 2009; 21: 373-378.

3. Miller RW, Young JL Jr., Novakovic B. Childhood cancer. Cancer 1995; 75: 395-405.

4. Yang L, Takimoto T, Fujimoto J. Prognostic model for predicting overall survival in children and adolescents with rhabdomyosarcoma. BMC Cancer 2014; 14: 654

5. Malempati S, Hawkins DS. Rhabdomyosarcoma: review of the Children's Oncology Group (COG) Soft-Tissue Sarcoma Committee experience and rationale for current COG studies. Pediatr Blood Cancer 2012; 59: 5-10.

6. Hanahan D, Weinberg RA. Hallmarks of cancer: the next generation. Cell 2011; 144: 646-674.

7. Fulda S. Tumor resistance to apoptosis. Int J Cancer 2009; 124: 511-515.

8. Fulda S, Debatin KM. Extrinsic versus intrinsic apoptosis pathways in anticancer chemotherapy. Oncogene 2006; 25: 4798-4811.

9. Adams J, Cory S. Bcl-2-regulated apoptosis: mechanism and therapeutic potential. Curr Opin Immunol 2007; 19: 488-496.

10. Fulda S, Galluzzi L, Kroemer G. Targeting mitochondria for cancer therapy. Nat Rev Drug Discov 2010; 9: 447-464.

11. Tait SWG, Green DR. Caspase-independent cell death: leaving the set without the final cut. Oncogene 2008; 27: 6452-6461.

12. Mei Y, Xie C, Xie W, Tian X, Li M, Wu M. Noxa/Mcl-1 balance regulates susceptibility of cells to camptothecin-induced apoptosis. Neoplasia 2007; 9: 871-881.

13. Dixon SJ, Lemberg KM, Lamprecht MR, Skouta R, Zaitsev EM, Gleason CE et al. Ferroptosis: an iron-dependent form of nonapoptotic cell death. Cell 2012; 149: 1060-1072.

14. Yang WS, Stockwell BR. Ferroptosis: death by lipid peroxidation. Trends Cell Biol 2016; 26: 165-176.

15. Trachootham D, Lu W, Ogasawara MA, Nilsa RD, Huang P. Redox regulation of cell survival. Antioxid Redox Signal 2008; 10: 1343-1374.

16. Liou GY, Storz P. Reactive oxygen species in cancer. Free Radic Res 2010; 44: 479-496.

17. Acharya A, Das I, Chandhok D, Saha T. Redox regulation in cancer: a double-edged sword with therapeutic potential. Oxid Med Cell Longev 2010; 3: 23-34.

18. Karlenius TC, Tonissen KF. Thioredoxin and cancer: a role for thioredoxin in all states of tumor oxygenation. Cancers (Basel) 2010; 2: 209-232.

19. Ortega AL, Mena S, Estrela JM. Glutathione in cancer cell death. Cancers (Basel) 2011; 3: 1285-1310.

20. Gorrini C, Harris IS, Mak TW. Modulation of oxidative stress as an anticancer strategy. Nat Rev Drug Discov 2013; 12: 931-947.

21. Mandal PK, Schneider M, Kolle P, Kuhlencordt P, Forster H, Beck H et al. Loss of thioredoxin reductase 1 renders tumors highly susceptible to pharmacologic glutathione deprivation. Cancer Res 2010; 70: 9505-9514.

22. Mandal PK, Seiler A, Perisic T, Kolle P, Banjac Canak A, Forster H et al. System x(c)- and thioredoxin reductase 1 cooperatively rescue glutathione deficiency. J Biol Chem 2010; 285 : 22244-22253.

23. Marty L, Siala W, Schwarzlander M, Fricker MD, Wirtz M, Sweetlove LJ et al. The NADPHdependent thioredoxin system constitutes a functional backup for cytosolic glutathione reductase in Arabidopsis. Proc Natl Acad Sci USA 2009; 106: 9109-9114.

24. Reichheld JP, Khafif M, Riondet C, Droux M, Bonnard G, Meyer Y. Inactivation of thioredoxin reductases reveals a complex interplay between thioredoxin and glutathione pathways in Arabidopsis development. Plant Cell 2007; 19: 1851-1865.

25. Tan SX, Greetham D, Raeth S, Grant CM, Dawes IW, Perrone GG. The thioredoxinthioredoxin reductase system can function in vivo as an alternative system to reduce oxidized glutathione in Saccharomyces cerevisiae. J Biol Chem 2010; 285: 6118-6126.

26. Griffith OW, Bridges RJ, Meister A. Transport of gamma-glutamyl amino acids: role of glutathione and gamma-glutamyl transpeptidase. Proc Natl Acad Sci USA 1979; 76: 6319-6322.

27. Meister A, Anderson ME. Glutathione. Annu Rev Biochem 1983; 52: 711-760.

28. Gromer S, Arscott LD, Williams CH Jr., Schirmer RH, Becker K. Human placenta thioredoxin reductase. Isolation of the selenoenzyme, steady state kinetics, and inhibition by therapeutic gold compounds. J Biol Chem 1998; 273: 20096-20101.

29. Holmgren A. Thioredoxin. Annu Rev Biochem 1985; 54: 237-271.

30. Liu N, Li X, Huang H, Zhao C, Liao S, Yang C et al. Clinically used antirheumatic agent auranofin is a proteasomal deubiquitinase inhibitor and inhibits tumor growth. Oncotarget 2014; 5: 5453-5471.

31. Chen X, Stewart E, Shelat AA, Qu C, Bahrami A, Hatley M et al. Targeting oxidative stress in embryonal rhabdomyosarcoma. Cancer Cell 2013; 24: 710-724.

32. Fan TWM, Kucia M, Jankowski K, Higashi RM, Ratajczak J, Ratajczak MZ et al. Rhabdomyosarcoma cells show an energy producing anabolic metabolic phenotype compared with primary myocytes. Mol Cancer 2008; 7: 79-79. 
33. Nijhawan D, Fang M, Traer E, Zhong Q, Gao W, Du F et al. Elimination of Mcl-1 is required for the initiation of apoptosis following ultraviolet irradiation. Genes Dev 2003; 17: 1475-1486.

34. Baou M, Kohlhaas SL, Butterworth M, Vogler M, Dinsdale D, Walewska R et al. Role of NOXA and its ubiquitination in proteasome inhibitor-induced apoptosis in chronic lymphocytic leukemia cells. Haematologica 2010; 95: 1510-1518.

35. Hjerpe R, Aillet F, Lopitz-Otsoa F, Lang V, England P, Rodriguez MS. Efficient protection and isolation of ubiquitylated proteins using tandem ubiquitin-binding entities. EMBO Rep 2009 10: $1250-1258$.

36. Oda E, Ohki R, Murasawa H, Nemoto J, Shibue T, Yamashita T et al. Noxa, a BH3-only member of the Bcl-2 family and candidate mediator of p53-induced apoptosis. Science 2000; 288: 1053-1058

37. Wei MC, Zong WX, Cheng EH, Lindsten T, Panoutsakopoulou V, Ross AJ et al. Proapoptotic BAX and BAK: a requisite gateway to mitochondrial dysfunction and death. Science 2001; 292: 727-730.

38. Kaufmann SH, Desnoyers S, Ottaviano Y, Davidson NE, Poirier GG. Specific proteolytic cleavage of poly(ADP-ribose) polymerase: an early marker of chemotherapy-induced apoptosis. Cancer Res 1993; 53: 3976-3985.

39. Hugle M, Belz K, Fulda S. Identification of synthetic lethality of PLK1 inhibition and microtubule-destabilizing drugs. Cell Death Differ 2015; 22: 1946-1956.

40. Brigelius-Flohe R, Maiorino M. Glutathione peroxidases. Biochim Biophys Acta 2013; 1830 3289-3303.

41. Drew R, Miners JO. The effects of buthionine sulphoximine (BSO) on glutathione depletion and xenobiotic biotransformation. Biochem Pharmacol 1984; 33: 2989-2994.

42. Albert A, Brauckmann C, Blaske F, Sperling M, Engelhard C, Karst U. Speciation analysis of the antirheumatic agent Auranofin and its thiol adducts by LC/ESI-MS and LC/ICP-MS. J Anal Atom Spectrom 2012; 27: 975-981.

43. Sadler PJ. The biological chemistry of gold. Gold Bull 1976; 9: 110-118.

44. Tomasovic A, Kurrle N, Surun D, Heidler J, Husnjak K, Poser I et al. Sestrin 2 protein regulates platelet-derived growth factor receptor beta (Pdgfrbeta) expression by modulating proteasomal and Nrf2 transcription factor functions. J Biol Chem 2015; 290: 9738-9752.

45. Wang X, Yen J, Kaiser P, Huang L. Regulation of the $26 \mathrm{~S}$ proteasome complex during oxidative stress. Sci Signal 2010; 3: ra88.
46. Health USNIoAuranofin in Treating Patients With Recurrent Epithelial Ovarian, Primary Peritoneal, or Fallopian Tube Cancer, vol. 2017.

47. Health USNIo. Phase I and II Study of Auranofin in Chronic Lymphocytic Leukemia (CLL), vol. 2017.

48. Furst DE. Mechanism of action, pharmacology, clinical efficacy and side effects of auranofin. An orally administered organic gold compound for the treatment of rheumatoid arthritis. Pharmacotherapy 1983; 3: 284-298.

49. Bailey HH, Mulcahy RT, Tutsch KD, Arzoomanian RZ, Alberti D, Tombes MB et al. Phase I clinical trial of intravenous L-buthionine sulfoximine and melphalan: an attempt at modulation of glutathione. J Clin Oncol 1994; 12: 194-205.

50. Fakler M, Loeder S, Vogler M, Schneider K, Jeremias I, Debatin KM et al. Small molecule XIAP inhibitors cooperate with TRAIL to induce apoptosis in childhood acute leukemia cells and overcome Bcl-2-mediated resistance. Blood 2009; 113: 1710-1722.

51. Fulda S, Strauss G, Meyer E, Debatin KM. Functional CD95 ligand and CD95 death-inducing signaling complex in activation-induced cell death and doxorubicin-induced apoptosis in leukemic T cells. Blood 2000; 95: 301-308.

52. Hacker S, Dittrich A, Mohr A, Schweitzer T, Rutkowski S, Krauss J et al. Histone deacetylase inhibitors cooperate with IFN-gamma to restore caspase-8 expression and overcome TRAIL resistance in cancers with silencing of caspase-8. Oncogene 2009; 28: 3097-3110.

(i) Cell Death and Disease is an open-access journal published by Nature Publishing Group. This work is licensed under a Creative Commons Attribution 4.0 International License. The images or other third party material in this article are included in the article's Creative Commons license, unless indicated otherwise in the credit line; if the material is not included under the Creative Commons license, users will need to obtain permission from the license holder to reproduce the material. To view a copy of this license, visit http://creativecommons.org/licenses/by/4.0/

(C) The Author(s) 2017

Supplementary Information accompanies this paper on Cell Death and Disease website (http://www.nature.com/cddis) 